\title{
Highly Stable Low Redox Potential Quinone for Aqueous Flow Batteries
}

3 Min Wu, ${ }^{1}$ Meisam Bahari, ${ }^{1}$ Yan Jing, ${ }^{2}$ Kiana Amini, ${ }^{1}$ Eric M. Fell,,${ }^{1}$ Thomas Y. George, ${ }^{1}$ Roy G.

4 Gordon, ${ }^{2 *}$ Michael J. Aziz ${ }^{1 *}$

$5{ }^{1}$ John A. Paulson School of Engineering and Applied Sciences, Harvard University, Cambridge,

6 Massachusetts 02138, United States

$7 \quad 2$ Department of Chemistry and Chemical Biology, Harvard University, Cambridge,

8 Massachusetts 02138, United States

9 Corresponding Authors

10 *gordon@chemistry.harvard.edu; * maziz@harvard.edu 


\section{Abstract}

Aqueous organic redox flow batteries are promising candidates for large-scale energy storage.

However, the design of stable and inexpensive electrolytes is challenging. Here, we report a highly stable, low redox potential, and potentially inexpensive negolyte species, sodium 3,3',3",3"'-((9,10anthraquinone-2,6-diyl)bis(azanetriyl))tetrakis(propane-1-sulfonate) (2,6-N-TSAQ), which is synthesized in a single step from inexpensive precursors. Pairing 2,6-N-TSAQ with potassium ferrocyanide at $\mathrm{pH} 14$ yielded a battery with the highest open-circuit voltage, $1.14 \mathrm{~V}$, of any anthraquinone-based cell with a capacity fade rate $<10 \% / \mathrm{yr}$. When $2,6-\mathrm{N}-\mathrm{TSAQ}$ was cycled at neutral $\mathrm{pH}$, it exhibited two orders of magnitude higher capacity fade rate. The great difference in anthraquinone cycling stability at different $\mathrm{pH}$ is interpreted in terms of the thermodynamics of the anthrone formation reaction. This work shows the great potential of organic synthetic chemistry for the development of viable flow battery electrolytes and demonstrates the remarkable performance improvements achievable with an understanding of decomposition mechanisms.

\section{Introduction}

Safe and economical energy storage technologies are indispensable for the deep penetration of intermittent renewable energies such as photovoltaic and wind electricity. ${ }^{1-3}$ Aqueous redox flow batteries are promising candidates for large-scale energy storage compared to other storage devices such as pumped-hydro, flywheel, and lithium-ion batteries, owing to the highly modular configuration, long cycle life, and good safety features. ${ }^{2,3}$ Aqueous vanadium redox flow batteries

31 (VRFBs) have been successfully established by many manufacturers, due to their long cycling life 
and high-power density. ${ }^{4}$ However, cost reductions in VRFBs are anticipated to be difficult due to the abundance of vanadium and its fluctuating price. Consequently, aqueous organic redox flow batteries (AORFBs) are attracting tremendous research interest, as the redox active materials comprising earth abundant elements are potentially inexpensive. ${ }^{3,5-7}$ Additionally, the physical and electrochemical properties of redox organics, such as aqueous solubility, molecular size, molecular net charge, redox potential, and chemical stability could be tailored for improved performance via molecular functionalization. 8,9 organics are susceptible to degradation reactions such as nucleophilic substitution, 41 disproportionation, and tautomerization. ${ }^{3}$ To date, various redox-active organics based on 42 quinone, ${ }^{8-21}$ viologen, ${ }^{22-31}$ phenazine, ${ }^{32-35}$ alloxazine, ${ }^{36}$ ferrocene ${ }^{23,}$ 24, 37, 38 and nitroxide radical derivatives $^{22,28,32,39}$ have been reported for AORFBs. Most of them, however, exhibit high

44 capacity fade rates of $0.1 \%-1 \% / \mathrm{day}^{3}$, which is unsuitable for practical application. Recently, anthraquinone derivatives such as 2,6-DBEAQ, 2,6-DPPEAQ, DPivOHAQ and DBAQ have demonstrated very good long-term stability. ${ }^{11,16,19}$ However, their widespread expensive precursors involved. Additionally, there is an apparent trade-off between 49 anthraquinone cycling stability and the redox potential. ${ }^{40}$ The highly stable 50 anthraquinones such as 2,6-DBEAQ, DPivOHAQ, and DBAQ have a redox potential

51 more positive than $-0.52 \mathrm{~V}$ vs. standard hydrogen electrode (SHE) at pH 12 and 
above; anthraquinones with a more negative redox potential exhibited less stable cycling performance. ${ }^{8}, 41$ For a negolyte molecule, however, a low redox potential is desired to achieve high cell voltage. Therefore, developing inexpensive and stable anthraquinone negolytes with a low redox potential remains crucial for the practical implementation of AORFBs.

Here, we report a potentially inexpensive and low redox-potential anthraquinone negolyte with outstanding cycling stability. The anthraquinone sodium 3,3',3",3"'-((9,10-anthraquinone-2,6diyl)bis(azanetriyl))tetrakis(propane-1-sulfonate) $\quad(2,6-\mathrm{N}-\mathrm{TSAQ}) \quad$ was $\quad$ synthesized from inexpensive 2,6-diaminoanthraquinone (2,6-DAAQ) via a one-step N-alkylation route. The redox potential of 2,6-N-TSAQ at $\mathrm{pH} 12$ and above is $-0.62 \mathrm{~V}$ vs. SHE, which is $120 \mathrm{mV}$ lower than that of the oxygen-linked anthraquinone sodium 3,3'-((9,10-anthraquinone-2,6diyl)bis(oxy))bis(propane-1-sulfonate) (2,6-O-DPSAQ) and $170 \mathrm{mV}$ lower than that of the carbonlinked anthraquinone sodium 3,3'-(9,10-anthraquinone-2,6-diyl)bis(propane-1-sulfonate) (2,6DPSAQ). Pairing with ferro/ferricyanide, it yields a cell with an open circuit potential of $1.14 \mathrm{~V}$ and a peak power density of $0.18 \mathrm{~W} / \mathrm{cm}^{2}$ at $\mathrm{pH} 14$. The capacity fade rate of 2,6-N-TSAQ is $0.025 \%$ /day at $\mathrm{pH} 14$, yielding the highest open-circuit voltage of any anthraquinone-based cell with a capacity fade $<10 \% / y r$. Greater capacity fade rates by up to two orders of magnitude at near-neutral $\mathrm{pH}$ are interpreted in terms of changes in the driving free energy for anthrone formation. These results provide guidance for improving the performance of anthraquinone negolytes and highlight the great potential of organic synthesis towards inexpensive and stable 
electrolytes for grid-scale energy storage application.

\section{Results and Discussion}

Figure 1 illustrates the synthetic routes for three different anthraquinones 2,6-N-TSAQ, 2,6-ODPSAQ and 2,6-DPSAQ. The structure of 2,6-N-TSAQ was verified by ${ }^{1} \mathrm{H}$ nuclear magnetic resonance (NMR) and high-resolution liquid chromatography-mass spectrometry as shown in Figure S1 and S2. The structures of 2,6-O-DPSAQ and 2,6-DPSAQ were verified by ${ }^{1} \mathrm{H}$ NMR as shown in Figure S3 and S4. Among them, 2,6-N-TSAQ and 2,6-O-DPSAQ were synthesized via similar one-step nucleophilic substitution reactions. 2,6-N-TSAQ was produced from 2,6-DAAQ, and 2,6-O-DPSAQ was synthesized from 2,6-dihydroxyanthraquinone (2,6-DHAQ). In both cases, sodium hydride was used to fully deprotonate the anthraquinone precursors in anhydrous dimethyl sulfoxide or N, N-dimethylformamide. Afterward, the deprotonated anthraquinone precursors react with 1,3-propanesultone overnight at room temperature to afford 2,6-N-TSAQ or 2,6-ODPSAQ. Benefiting from the high reactivity of 1,3-propanesultone, the reaction is readily performed at room temperature with high purity and yield, making it very suitable for mass production. In contrast, 2,6-DPSAQ was synthesized from 2,6-DAAQ with three steps. ${ }^{42}$ First, 2,6-DAAQ was converted to 2,6-diiodoanthraquinone. Afterward, it reacted with sodium allylsulfonate via Heck reaction followed by a hydrogenation step to yield 2,6-DPSAQ. The threestep reaction involving precious metal catalysts makes it less attractive compared with the onestep synthesis of 2,6-N-TSAQ and 2,6-O-DPSAQ. Since the laboratory cost of precursor 2,6- 
DAAQ is much lower than that of 2,6-DHAQ (Table S1), 2,6-N-TSAQ could be the most of AORFBs.
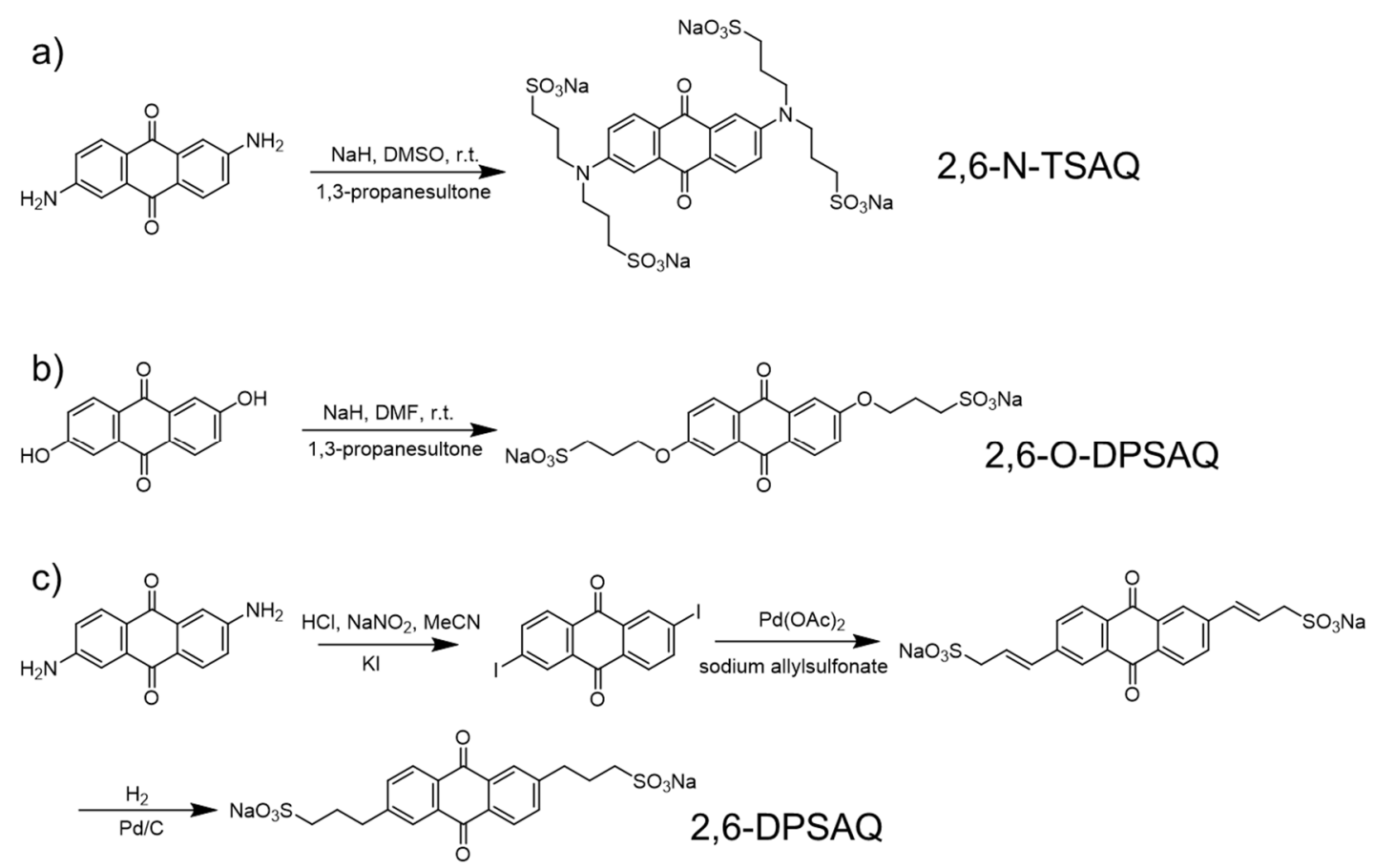

Figure 1. Synthetic routes for three different anthraquinones. a) 2,6-N-TSAQ; b) 2,6-O-DPSAQ;

Figure 2a exhibits the cyclic voltammograms (CV) of 2,6-DPSAQ, 2,6-O-DPSAQ, and 2,6and $170 \mathrm{mV}$ lower than that of 2,6-O-DPSAQ and 2,6-DPSAQ in $1 \mathrm{M} \mathrm{NaCl}$, respectively. The low redox potential of 2,6-N-TSAQ is attributed to the strong electron donating effect of nitrogen lone pairs. It contributes to form a high working voltage and high-power density flow battery. The CV of 2,6-N-TSAQ in $1 \mathrm{M} \mathrm{NaOH}$ is shown in Figure S5. The redox potential of 2,6-N-TSAQ at $\mathrm{pH}$ 
14 is $-0.63 \mathrm{~V}$ vs. SHE, which is close to that in $1 \mathrm{M}$ sodium chloride medium. But the peak separation of 2,6-N-TSAQ in $1 \mathrm{M} \mathrm{NaOH}(94 \mathrm{mV})$ is much smaller than that in $1 \mathrm{M} \mathrm{NaCl}(130$ $\mathrm{mV}$ ), indicating a much faster redox process at $\mathrm{pH} 14$ than that at lower $\mathrm{pH}$. The water solubility of 2,6-DPSAQ, 2,6-O-DPSAQ, and 2,6-N-TSAQ is shown in Figure 2b. Surprisingly, 2,6-ODPSAQ exhibited an extremely low solubility of $10 \mathrm{mM}$ in deionized water and in $1 \mathrm{M}$ lithium chloride, and an even lower solubility of less than $5 \mathrm{mM}$ in $1 \mathrm{M}$ sodium chloride. The solubilities of 2,6-DPSAQ and 2,6-N-TSAQ in deionized-water (no supporting salt) are $0.3 \mathrm{M}$ and $0.45 \mathrm{M}$, respectively.
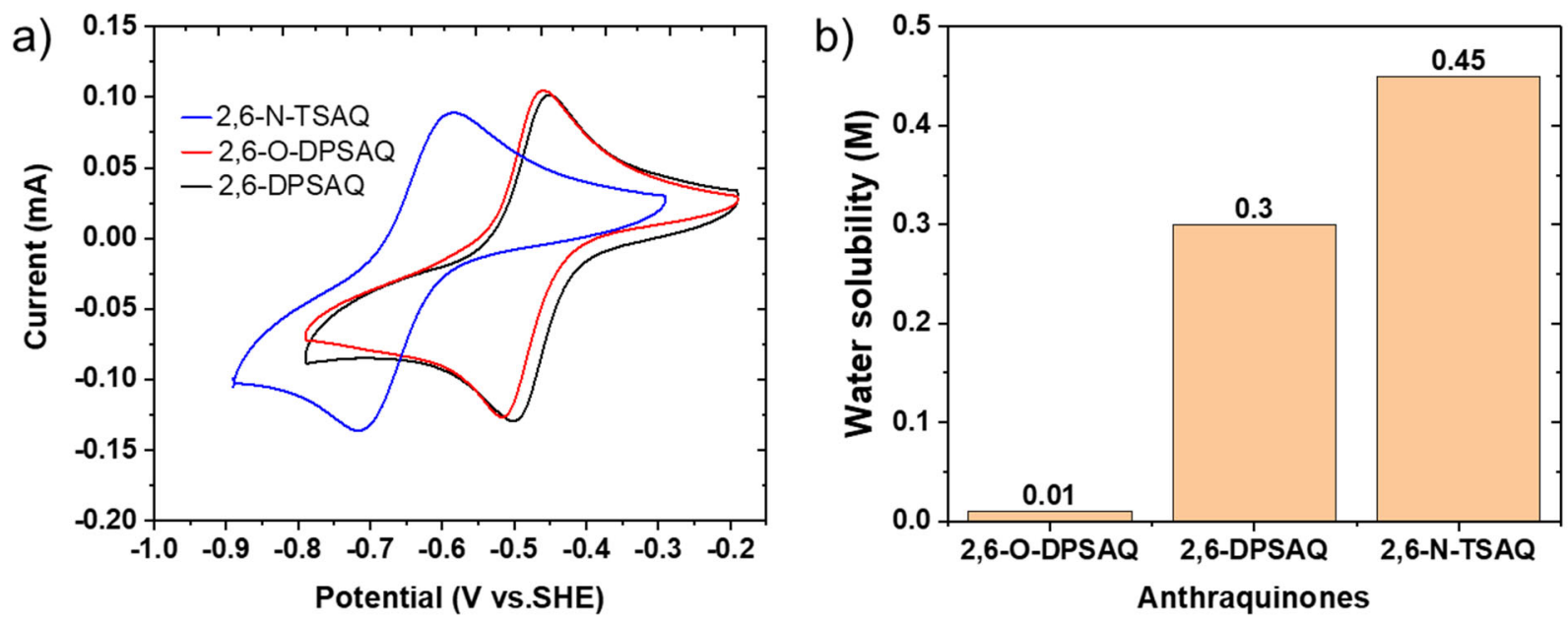

Figure 2. a) Cyclic voltammograms of $5 \mathrm{mM}$ 2,6-N-TSAQ and $5 \mathrm{mM}$ 2,6-DPSAQ in 1 M sodium chloride, and $5 \mathrm{mM}$ 2,6-O-TSAQ in $1 \mathrm{M}$ lithium chloride, each with a scan rate of $100 \mathrm{mV} / \mathrm{s}$; b) Solubility comparison for 2,6-N-TSAQ, 2,6-O-DPSAQ and 2,6-DPSAQ in deionized water.

Given the higher water solubility, lower redox potential, and possible lower synthetic cost, 2,6-N-TSAQ was selected for further electrochemical study. The advantage of 2,6-N-TSAQ over 
120 some other low redox potential anthraquinones ${ }^{8,41}$ is that it has four negative charges on the 121 solubilizing groups, leading to a high intermolecular Coulomb repulsion and a low collision rate.

122 According to Marcus theory, ${ }^{43}, 44$ these properties could decrease the reaction rate of the 123 disproportionation (known to cause capacity decay in anthraquinone negolyte). ${ }^{19}$, 40 The large 124 Coulomb repulsion and bulky functionalization also decrease the molecular permeability across 125 126 through sodium-exchanged Nafion NR212 was measured in a two-compartment diffusion cell. Due to a very low crossover rate, we estimate a maximum permeability of $3 \times 10^{-14} \mathrm{~cm}^{2} / \mathrm{s}$ (Figures S6 and S7), which is even lower than that reported for the tetra-anionic anthraquinone derivative 2,6-DPPEAQ. ${ }^{16}$

The Pourbaix diagram of 2,6-N-TSAQ, shown in Figure 3a, indicates the molecule undergoes a two-proton/two-electron process below $\mathrm{pH}$ 10, a one-proton/two-electron process over $\mathrm{pH} 10$ 12 , and a $\mathrm{pH}$-independent two-electron process at $\mathrm{pH}>12$ with a redox potential around $-0.63 \mathrm{~V}$ vs. SHE. The corresponding CV profiles at various $\mathrm{pH}$ are shown in Figure S8. It should be noted that the $\mathrm{pH}$ is the local $\mathrm{pH}$ of anthraquinone molecules. For an unbuffered case, e.g., $1 \mathrm{M} \mathrm{NaCl}$, the formal potential of $2,6-\mathrm{N}-\mathrm{TSAQ}$ is $-0.62 \mathrm{~V}$, which is close to the redox potential at high $\mathrm{pH}$; such a phenomenon was also observed in other anthraquinones when a $\mathrm{pH}$ buffer was not used. ${ }^{16}$, ${ }^{17}$ Based on the Pourbaix diagram, the $\mathrm{pKa} 1$ and $\mathrm{pKa} 2$ of reduced and protonated 2,6-N-TSAQ are estimated to have values around 10 and 12 , respectively, which are slightly larger than those of anthraquinone negolytes with more positive redox potentials. ${ }^{9}, 11,16,19 \mathrm{We}$ attribute this to the strong 
141 groups of the 9,10-dihydroxyanthracene (reduced state of anthraquinone).
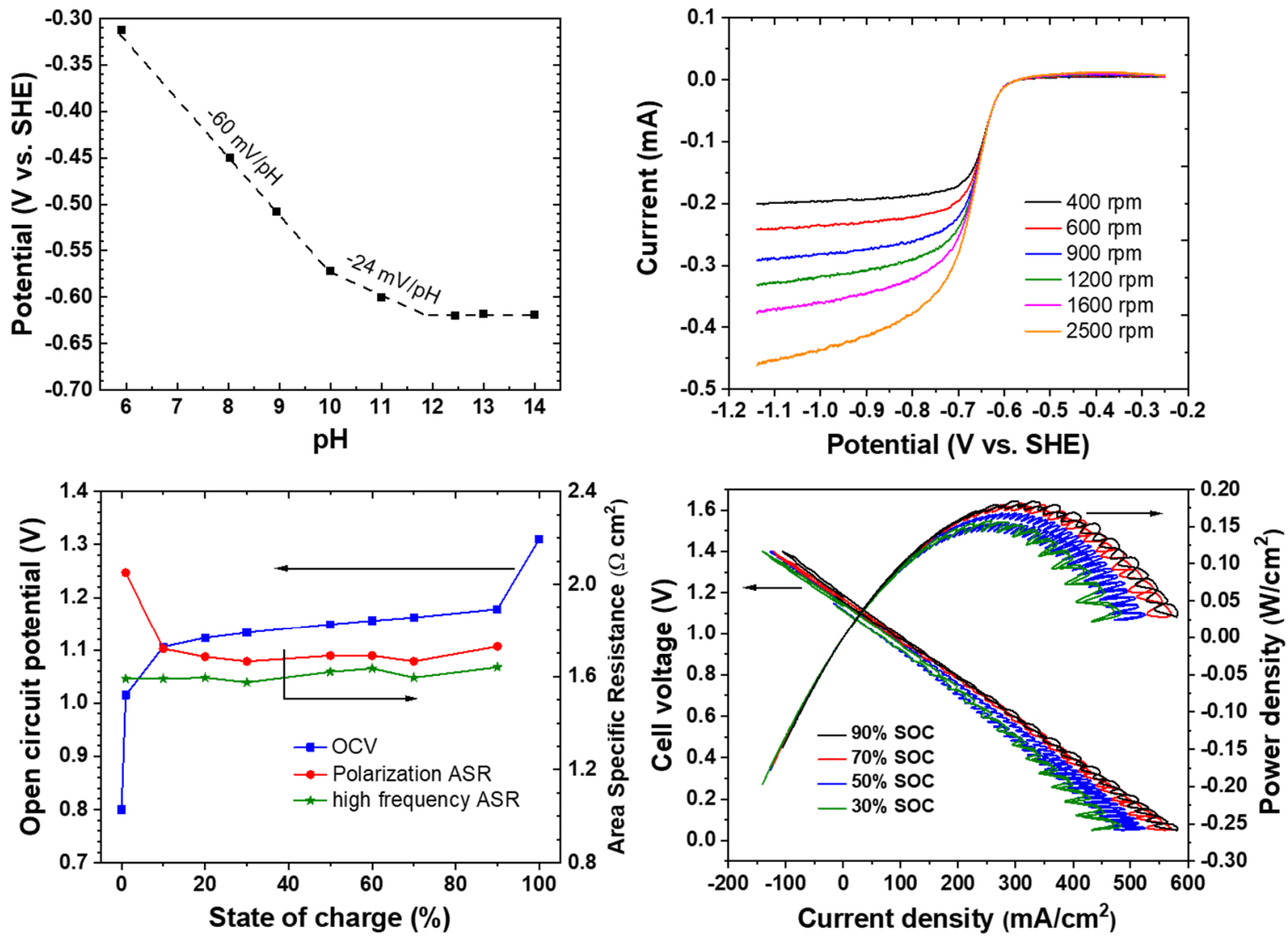

Figure 3. Electrochemical performance of 2,6-N-TSAQ. a) Pourbaix diagram of 2,6-N-TSAQ redox process; b) at rotation rates between 400 and $2500 \mathrm{rpm}$; c) Open circuit voltage (OCV), high-frequency area-specific resistance (ASR) and polarization ASR versus SOC of 2,6-N-TSAQ/potassium ferrocyanide full cell at pH 14; cloth electrodes. 

(RDE) test as shown in Figures 3 b and S9. The diffusion coefficient $(D)$ was calculated to be $5.8 \times 10^{-7} \mathrm{~cm}^{2} / \mathrm{s}$ by the Levich equation. The charge transfer coefficient was determined to be 0.32 based on the Tafel equation, and the electron transfer rate constant was determined to be $2.53 \times 10^{-4}$ $155 \mathrm{~cm} \mathrm{~s}^{-1}$.

Polarization experiments of a $0.1 \mathrm{M} 2,6-\mathrm{N}-\mathrm{TSAQ} /$ ferrocyanide full cell at $\mathrm{pH} 14$ were performed at various states of charge. The electrolytes comprised $5 \mathrm{~mL}$ of $0.1 \mathrm{M}$ 2,6-N-TSAQ (negolyte) at $\mathrm{pH} 14$ and $30 \mathrm{~mL}$ of $0.1 \mathrm{M}$ potassium ferrocyanide and $0.02 \mathrm{M}$ potassium ferricyanide (posolyte) at $\mathrm{pH} 14$ to ensure that the negolyte was always the capacity limiting side. The cell was constructed from graphite flow plates and AvCarb carbon cloth electrodes, separated by a Nafion 212 membrane ion exchanged in $1 \mathrm{M} \mathrm{NaOH}$ for over 12 hours at room temperature. The electrolyte was charged/discharged at $40 \mathrm{~mA} / \mathrm{cm}^{2}$ between $0.6 \mathrm{~V}$ and $1.4 \mathrm{~V}$ with a potential hold until the current dropped to $2 \mathrm{~mA} / \mathrm{cm}^{2}$ to get the full capacity. The OCV increased from 0.8 to $1.31 \mathrm{~V}$ as the SOC increased from $\sim 0 \%$ to $\sim 100 \%$ (Figure 3a). The $0.2 \mathrm{~V}$ increase of OCV from 0 to $\sim 1 \% \mathrm{SOC}$, $0.09 \mathrm{~V}$ increase from $\sim 1 \%$ to $\sim 10 \%, 0.08 \mathrm{~V}$ increase from $10 \%$ to $90 \% \mathrm{SOC}$, and $0.14 \mathrm{~V}$ from $90 \%$ to final OCV, indicates the utilization of $2,6-\mathrm{N}-\mathrm{TSAQ}$ is more than $99 \%$ under the operating conditions according to the Nernst equation. The peak galvanic power density at $10 \% \mathrm{SOC}$ was $0.15 \mathrm{~W} \mathrm{~cm}^{-2}$ and increased to $0.18 \mathrm{~W} \mathrm{~cm}^{-2}$ at $90 \%$ SOC (Figure $3 \mathrm{~d}$ ). The power density is mainly limited by the high-frequency ASR, which is dominated by the membrane resistance (Figure 3c) with a value around $1.6 \Omega \cdot \mathrm{cm}^{2}$. Therefore, the power density is expected to be improved with a 
171 lower-resistance membrane.

172 A long-term cycling test of the $0.1 \mathrm{M}$ 2,6-N-TSAQ/ferrocyanide flow battery at $\mathrm{pH} 14$ was 173 performed with the same cell. The cell was cycled at $40 \mathrm{~mA} \mathrm{~cm}^{-2}$ with potential holds at $1.4 \mathrm{~V}$ for 174 charging and $0.6 \mathrm{~V}$ for discharging until the current density dropped to $2 \mathrm{~mA} \mathrm{~cm}^{-2}$. The initial 175 volumetric discharge capacity was $4.76 \mathrm{Ah} / \mathrm{L}$, corresponding to a capacity utilization of $88.9 \%$ of 176 the theoretical value. However, the OCV at different SOCs in Figure $\mathbf{3 c}$ and the typical voltage 177 profile in Figure 4c indicates it achieves full capacity of 2,6-N-TSAQ under such conditions. The 178 difference between realized capacity and the theoretical value could come from errors in 179 electrolyte volume measurement or the presence of non-redox active impurities such as water or 180 salts in the sample. After 9 days of full SOC range cycling, the discharge capacity decreased to 4.75 $\mathrm{Ah} / \mathrm{L}$, corresponding to a temporal capacity fade rate of $0.025 \% /$ day or $0.00024 \% /$ cycle. The average coulombic efficiency was determined to be above $99.9 \%$. The voltage/capacity profile at different cycles in Figure $4 \mathrm{c}$ are almost invariant, indicating the highly-stable cell performance of 2,6-N-TSAQ at $\mathrm{pH}$ 14. This high cycling stability is achieved in an anthraquinone molecule with 

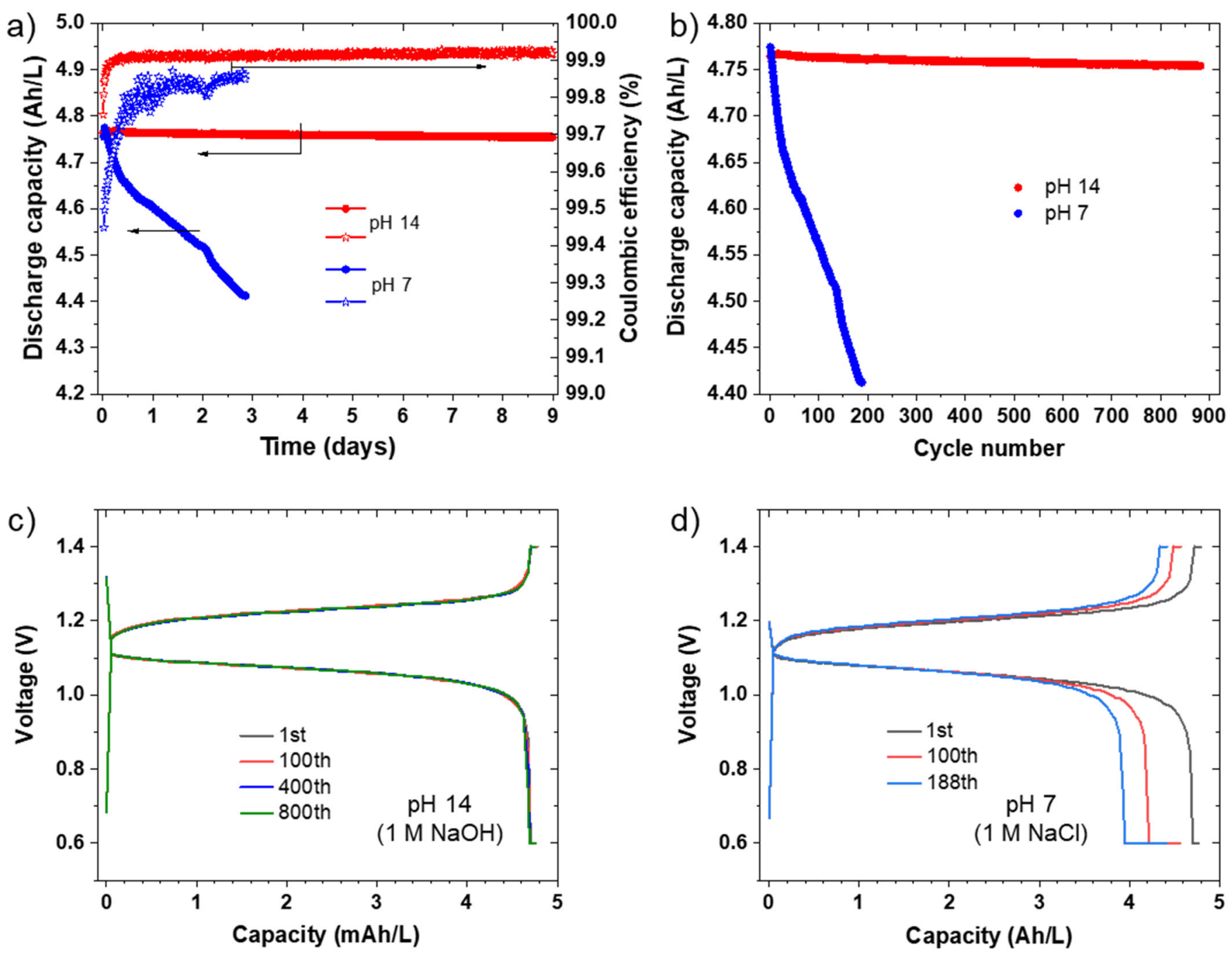

187 Figure 4. Cell performance of $0.1 \mathrm{M}$ 2,6-N-TSAQ/ferrocyanide cell, 2,6-N-TSAQ as the capacity

188 limiting side. a) Discharge capacity and Coulombic efficiency versus cycle time at pH 7 and 14;

b) Discharge capacity versus cycle number at pH 7 and 14; c) Charge-discharge voltage profile of

2,6-N-TSAQ from selected cycles at $\mathrm{pH} 14$ in Figure 4b; d) Charge-discharge voltage profile of 

under the same electrolyte volume, cut-off voltage and current for comparison. The initial volumetric capacity was $4.77 \mathrm{Ah} / \mathrm{L}$ and after 2.84 days cycling, the discharge capacity dropped to 4.41 Ah/L, corresponding to a capacity fade rate of $2.6 \% /$ day, which is around 2 orders of magnitude higher than that at $\mathrm{pH} 14$. The coulombic efficiency was around $99.8 \%$ over the whole the discharge capacity from the constant potential hold at $0.6 \mathrm{~V}$ increases and round-trip energy

201

efficiency decreases as the cycle count increases.

An otherwise-identical $0.1 \mathrm{M} 2,6-\mathrm{N}-\mathrm{TSAQ} /$ ferrocyanide full cell was cycled in $1 \mathrm{M} \mathrm{NH} 4 \mathrm{Cl}$ enabling the $\mathrm{pH}$ to remain below 10 over the entire SOC range. The initial charge capacity was up to $4.98 \mathrm{Ah} / \mathrm{L}$ but the initial discharge capacity was only $0.50 \mathrm{Ah} / \mathrm{L}$ with a low coulombic efficiency of $10.1 \%$ as shown in Figure S11. The discharge capacity dropped to $0.29 \mathrm{Ah} / \mathrm{L}$ in the third cycle with a coulombic efficiency around $80 \%$. The ${ }^{1} \mathrm{H}$ NMR spectrum for the cycled 2,6-N-TSAQ $\left(\mathrm{NH}_{4}{ }^{+}\right)$is shown in Figure S12. The five peaks with asterisks in the aromatic region are similar to the anthrone peaks observed in $2,6-\mathrm{DHAQ},{ }^{40}$ suggesting that the major decomposition of 2,6-NTSAQ came from anthrone formation. After the electrolyte was fully oxidized by exposure to air, the five peaks with asterisks disappeared and some new peaks appeared, suggesting that the anthrone was oxidized to anthraquinone and anthrone dimer. ${ }^{19,}{ }^{40}$ Furthermore, mass spectrometry was used to analyze the cycled 2,6-N-TSAQ $\left(\mathrm{NH}_{4}{ }^{+}\right)$electrolyte, and anthrone was detected as the major decomposition compound (Figure S13). 

fixed at a certain value can be expressed as $\Delta G^{\circ \prime}=-2 \times F \times\left(E_{2}-E_{1}\right)$, where $E_{1}$ and $E_{2}$ are the redox potentials of the two half-reactions under these conditions. The proposed Pourbaix diagram protonation of the molecules on the left-hand side of Reactions I and II is illustrated in the intermediate-potential band of the Pourbaix diagram. When the local $\mathrm{pH}<\mathrm{pKa} 1$, both half reactions undergo a two-proton/two-electron process. When the local $\mathrm{pH}$ is between $\mathrm{p} K \mathrm{a} 1$ and $\mathrm{p} K \mathrm{a}$, reaction I undergoes a one-proton/two-electron process, and reaction II undergoes a three- 
234 electron process, while reaction II undergoes a two-proton/two-electron process. When $\mathrm{pH}$ is 235 above $\mathrm{pKa} 2$, half reaction I becomes $\mathrm{pH}$ independent, and half reaction II undergoes a three236 proton/two-electron reaction. As shown in Figure 5b, the Gibbs free energy change for anthrone 237 formation is around $\Delta\left(\Delta G^{\circ}\right)=-2 \times \frac{96485 C}{m o l} \times \frac{-\frac{0.089 \mathrm{~V}}{p H} \times 2 p H}{1000}=34 \mathrm{~kJ} / \mathrm{mol}$ less negative at $\mathrm{pH} 14$ 238 than that at $\mathrm{pH}$ 12. Similarly, the difference in Gibbs free energy change per mole of anthrone 239 formation at $\mathrm{pH} 14$ and 10 could be as large as $-2 \times 96485 \times(0.089 \times 3+0.0295 \times 1) / 1000=$ $24057 \mathrm{~kJ} / \mathrm{mol}$, if $\mathrm{pKa}$ is around 10 and $\mathrm{pKa}$ is around 11 . Therefore, anthrone formation becomes 241 significantly more disfavored at $\mathrm{pH} 14$ than that at a significantly lower $\mathrm{pH}$. Consequently, when 242 anthrone formation is the predominant decomposition mechanism, anthraquinone-based flow 243 batteries exhibit better cycling performance at high $\mathrm{pH}$ than that at lower $\mathrm{pH}$. Moreover, the Gibbs 244 free energy change for the anthrone formation reaction at a $100 \%$ SOC (no anthrone and 245 anthraquinone, $100 \% 9,10$-dihydroxyanthracene) is always negative, indicating that for any given 246 anthraquinone, the disproportionation reaction at the full SOC is always thermodynamically 247 favorable. When the SOC of anthraquinone increases from $90 \%$ to $99 \%$, the Gibbs free energy 248 change for anthrone formation becomes more negative by approximately 249 $8.314 \mathrm{~J} / \mathrm{mol} / \mathrm{K} \times 298.15 \mathrm{~K} \times\left(\ln \frac{0.1}{0.9^{2}}-\ln \frac{0.01}{0.99^{2}}\right)=6.18 \mathrm{~kJ} / \mathrm{mol}$ assuming the variation of anthrone 250 concentration is negligible. Likewise, when the SOC of anthraquinone negolyte increases from $90 \%$ 251 to $99.9 \%$, the Gibbs free energy change for anthrone formation becomes more negative by 252 approximately $11.93 \mathrm{~kJ} / \mathrm{mol}$. Therefore, to suppress anthrone formation in practical deployment, 253 charging to a high SOC should be avoided, i.e., it is desired not to conduct a potential hold at the 
255 in research to evaluate very low capacity fade rates. ${ }^{3,45}$. For future research on anthraquinone 256 negolytes species, a potential hold after, say, every 30 cycles of galvanostatic cycling might be 257 advisable.

a)

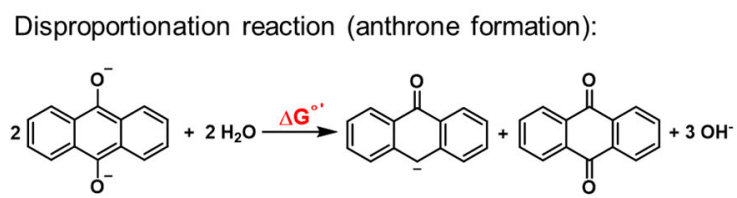

Half reactions:

Reaction I:

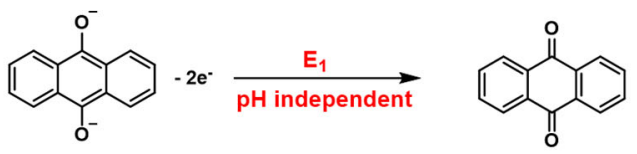

Reaction II:

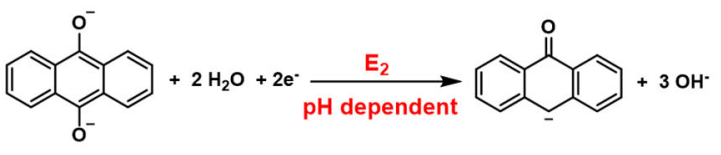

b)

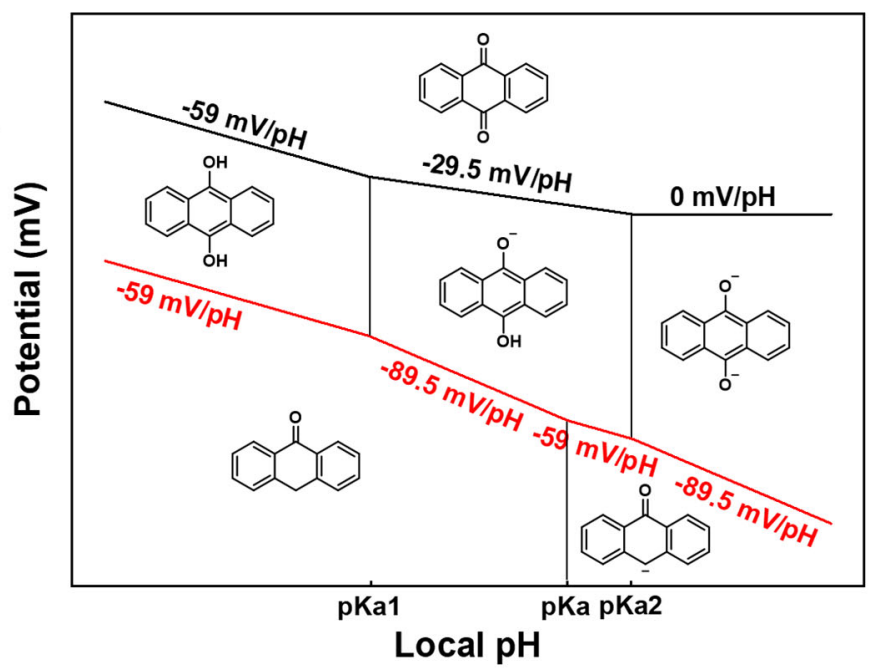

259

260

261

262

263

264

265

Figure 5. a) Disproportionation reaction of 9,10-dihydroxyanthraceen at $\mathrm{pH}$ above its $\mathrm{pKa} 2$ and the corresponding two half reactions; b) Representative Pourbaix diagram of anthraquinone, 9,10dihydroxyanthracene, and anthrone. The $\mathrm{pKa} 1$ and $\mathrm{pKa}$ belong to 9,10-dihydroxyanthracene, and $\mathrm{pKa}$ (around 10) belongs to anthrone. ${ }^{46}$ The water molecules in the half reactions were neglected in Figure $5 b$ due to the space limitation.

In summary, we synthesized three sulfonated anthraquinone derivatives, carbon-linked, nitrogen-linked, and oxygen-linked. The nitrogen-linked anthraquinone (2,6-N-TSAQ) showed a much lower redox potential than the others due to the strongest electron donating effect of lone pair electrons on nitrogen atoms. Because it is synthesized from inexpensive precursor with a one- 
step N-alkylation method, the mass production cost could be low. Despite the Coulomb repulsion afforded by its four negatively charged sulfonate groups, the cycling performance of 2,6-N-TSAQ is poor at neutral $\mathrm{pH}$, with a capacity fade rate of $2.6 \% /$ day. The cycling stability improved by two stability at different $\mathrm{pH}$ values is explained in terms of the thermodynamics of anthrone formation.

This work demonstrates the significant improvement in performance that can be made with a better

277 chemistry for low-cost and stable AORFB electrolytes.

278 Supporting Information. The Supporting Information is available free of charge at

\section{ACKNOWLEDGMENT}

280 This research was supported by the U.S. National Science Foundation through grant CBET-

2811914543 and by U.S. DOE award DE-AC05-76RL01830 through PNNL subcontract 535264.

282 The authors thank Martin Jin, Emily Kerr, Daniel Pollack, and Jinxu Gao for valuable

283 discussions. 
285 M.B., R.G.G. and M.J.A. have ownership stakes in Quino Energy, Inc., which may profit from 286 the results reported here. 


\section{References}

289

290

291

292

293

294

295

296

297

298

299

300

301

302

303

304

305

306

307

308

309

310

311

312

313 314

1. Dunn, B.; Kamath, H.; Tarascon, J. M., Electrical energy storage for the grid: a battery of choices. Science 2011, 334 (6058), 928-35.

2. Soloveichik, G. L., Flow Batteries: Current Status and Trends. Chem Rev 2015, 115 (20), 11533-58.

3. Kwabi, D. G.; Ji, Y.; Aziz, M. J., Electrolyte lifetime in aqueous organic redox flow batteries: A critical review. Chem Rev 2020, 120 (14), 6467-6489.

4. Ulaganathan, M.; Aravindan, V.; Yan, Q.; Madhavi, S.; Skyllas-Kazacos, M.; Lim, T. M., Recent Advancements in All-Vanadium Redox Flow Batteries. Advanced Materials Interfaces 2016, 3 (1), 1500309.

5. Luo, J. A.; Hu, B.; Hu, M. W.; Zhao, Y.; Liu, T. L., Status and Prospects of Organic Redox Flow Batteries toward Sustainable Energy Storage. ACS Energy Letters 2019, 4 (9), 22202240.

6. Winsberg, J.; Hagemann, T.; Janoschka, T.; Hager, M. D.; Schubert, U. S., Redox-Flow Batteries: From Metals to Organic Redox-Active Materials. Angew Chem Int Ed 2017, 56 (3), 686711.

7. Wei, X. L.; Pan, W. X.; Duan, W. T.; Hollas, A.; Yang, Z.; Li, B.; Nie, Z. M.; Liu, J.; Reed, D.; Wang, W.; Sprenkle, V., Materials and Systems for Organic Redox Flow Batteries: Status and Challenges. ACS Energy Letters 2017, 2 (9), 2187-2204.

8. Lin, K.; Chen, Q.; Gerhardt, M. R.; Tong, L.; Kim, S. B.; Eisenach, L.; Valle, A. W.; Hardee, D.; Gordon, R. G.; Aziz, M. J.; Marshak, M. P., Alkaline quinone flow battery. Science 2015, 349 (6255), 1529-32.

9. Huskinson, B. T.; Marshak, M. P.; Suh, C.; Er, S.; Gerhardt, M. R.; Galvin, C. J.; Chen, X.; Aspuru-Guzik, A.; Gordon, R. G.; Aziz, M. J., A metal-free organic-inorganic aqueous flow battery. Nature 2014, 505 (7482), 195-8.

13 10. Gerhardt, M. R.; Tong, L.; Gomez-Bombarelli, R.; Chen, Q.; Marshak, M. P.; Galvin, C. J.; Aspuru-Guzik, A.; Gordon, R. G.; Aziz, M. J., Anthraquinone Derivatives in Aqueous 
Flow Batteries. Advanced Energy Materials 2017, 7 (8), 1601488.

11. Kwabi, D. G.; Lin, K.; Ji, Y.; Kerr, E. F.; Goulet, M.-A.; De Porcellinis, D.; Tabor, D. P.; Pollack, D. A.; Aspuru-Guzik, A.; Gordon, R. G.; Aziz, M. J., Alkaline quinone flow battery with long lifetime at pH 12. Joule 2018, 2 (9), 1907-1908.

12. Cao, J. Y.; Tao, M.; Chen, H. P.; Xu, J.; Chen, Z. D., A highly reversible anthraquinonebased anolyte for alkaline aqueous redox flow batteries. Journal of Power Sources 2018, 386, 4046.

13. Yang, Z.; Tong, L.; Tabor, D. P.; Beh, E. S.; Goulet, M. A.; De Porcellinis, D.; Aspuru-Guzik, A.; Gordon, R. G.; Aziz, M. J., Alkaline Benzoquinone Aqueous Flow Battery for Large-Scale Storage of Electrical Energy. Advanced Energy Materials 2018, 8 (8), 1702056. 14. Wang, C. X.; Yang, Z.; Wang, Y. R.; Zhao, P. Y.; Yan, W.; Zhu, G. Y.; Ma, L. B.; Yu, B.; Wang, L.; Li, G. G.; Liu, J.; Jin, Z., High-Performance Alkaline Organic Redox Flow Batteries Based on 2-Hydroxy-3-carboxy-1,4-naphthoquinone. Acs Energy Letters 2018, 3 (10), 2404-2409.

15. Tong, L.; Goulet, M.-A.; Tabor, D. P.; Kerr, E. F.; De Porcellinis, D.; Fell, E. M.; Aspuru-Guzik, A.; Gordon, R. G.; Aziz, M. J., Molecular Engineering of an Alkaline Naphthoquinone Flow Battery. ACS Energy Letters 2019, 4 (8), 1880-1887.

16. Ji, Y.; Goulet, M. A.; Pollack, D. A.; Kwabi, D. G.; Jin, S.; Porcellinis, D.; Kerr, E. F.; Gordon, R. G.; Aziz, M. J., A Phosphonate-Functionalized Quinone Redox Flow Battery at Near-Neutral pH with Record Capacity Retention Rate. Advanced Energy Materials 2019, 9 (12), 1900039.

17. Jin, S.; Jing, Y.; Kwabi, D. G.; Ji, Y.; Tong, L.; De Porcellinis, D.; Goulet, M. A.; Pollack, D. A.; Gordon, R. G.; Aziz, M. J., A water-miscible quinone flow battery with high volumetric capacity and energy density. ACS Energy Letters 2019, 4 (6), 1342-1348.

18. Hu, B.; Luo, J.; Hu, M.; Yuan, B.; Liu, T. L., A pH-Neutral, Metal-Free Aqueous Organic Redox Flow Battery Employing an Ammonium Anthraquinone Anolyte. Angew Chem Int 2019, $58(46), 16629-16636$. 
19. Wu, M.; Jing, Y.; Wong, A. A.; Fell, E. M.; Jin, S.; Tang, Z.; Gordon, R. G.; Aziz, M. J., Extremely stable anthraquinone negolytes synthesized from common precursors. Chem 2020, 6,11 .

20. Jing, Y.; Wu, M.; Wong, A. A.; Fell, E. M.; Jin, S.; Pollack, D. A.; Kerr, E. F.; Gordon, R. G.; Aziz, M. J., In situ electrosynthesis of anthraquinone electrolytes in aqueous flow batteries. Green Chemistry 2020, 22 (18), 6084-6092.

21. Wu, M.; Bahari, M.; Fell, E.; Gordon, R. G.; Aziz, M. J., High-Performance Anthraquinone with Potentially Low Cost for Aqueous Redox Flow Batteries. Journal of Materials Chemistry A 2021. https://doi.org/10.1039/D1TA08900E.

22. Liu, T. B.; Wei, X. L.; Nie, Z. M.; Sprenkle, V.; Wang, W., A Total Organic Aqueous Redox Flow Battery Employing a Low Cost and Sustainable Methyl Viologen Anolyte and 4-HOTEMPO Catholyte. Advanced Energy Materials 2015, 6 (3), 1501449.

23. Hu, B.; DeBruler, C.; Rhodes, Z.; Liu, T. L., Long-Cycling Aqueous Organic Redox Flow Battery (AORFB) toward Sustainable and Safe Energy Storage. J Am Chem Soc 2017, 139 (3), 1207-1214.

24. Beh, E. S.; De Porcellinis, D.; Gracia, R. L.; Xia, K. T.; Gordon, R. G.; Aziz, M. J., A Neutral pH Aqueous Organic-Organometallic Redox Flow Battery with Extremely High Capacity Retention. ACS Energy Letters 2017, 2 (3), 639-644.

25. Luo, J.; Hu, B.; Debruler, C.; Liu, T. L., A pi-Conjugation Extended Viologen as a TwoElectron Storage Anolyte for Total Organic Aqueous Redox Flow Batteries. Angew Chem Int Ed 2018, 57 (1), 231-235.

26. Hu, B.; Tang, Y.; Luo, J.; Grove, G.; Guo, Y.; Liu, T. L., Improved radical stability of viologen anolytes in aqueous organic redox flow batteries. Chem Commun 2018, 54 (50), 6871 6874.

27. DeBruler, C.; Hu, B.; Moss, J.; Luo, J.; Liu, T. L., A Sulfonate-Functionalized Viologen Enabling Neutral Cation Exchange, Aqueous Organic Redox Flow Batteries toward Renewable Energy Storage. ACS Energy Letters 2018, 3 (3), 663-668. 
28. Liu, Y. H.; Goulet, M. A.; Tong, L. C.; Liu, Y. Z.; Ji, Y. L.; Wu, L.; Gordon, R. G.; Aziz, M. J.; Yang, Z. J.; Xu, T. W., A Long-Lifetime All-Organic Aqueous Flow Battery Utilizing TMAP-TEMPO Radical. Chem 2019, 5 (7), 1861-1870.

29. Liu, W.; Liu, Y.; Zhang, H.; Xie, C.; Shi, L.; Zhou, Y. G.; Li, X., A highly stable neutral viologen/bromine aqueous flow battery with high energy and power density. Chem Commun 2019, 55 (33), 4801-4804.

30. Jin, S.; Fell, E. M.; Vina-Lopez, L.; Jing, Y.; Michalak, P. W.; Gordon, R. G.; Aziz, M. J., Near Neutral pH Redox Flow Battery with Low Permeability and Long-Lifetime Phosphonated Viologen Active Species. Advanced Energy Materials 2020, 10 (20), 2000100.

31. Liu, Y.; Li, Y.; Zuo, P.; Chen, Q.; Tang, G.; Sun, P.; Yang, Z.; Xu, T., Screening Viologen Derivatives for Neutral Aqueous Organic Redox Flow Batteries. ChemSusChem 2020, $13,2245-2249$.

32. Winsberg, J.; Stolze, C.; Muench, S.; Liedl, F.; Hager, M. D.; Schubert, U. S., TEMPO/Phenazine Combi-Molecule: A Redox-Active Material for Symmetric Aqueous RedoxFlow Batteries. ACS Energy Letters 2016, 1 (5), 976-980.

33. Hollas, A.; Wei, X. L.; Murugesan, V.; Nie, Z. M.; Li, B.; Reed, D.; Liu, J.; Sprenkle, V.; Wang, W., A biomimetic high-capacity phenazine-based anolyte for aqueous organic redox flow batteries. Nature Energy 2018, 3 (6), 508-514.

34. Wang, C.; Li, X.; Yu, B.; Wang, Y.; Yang, Z.; Wang, H.; Lin, H.; Ma, J.; Li, G.; Jin, Z., Molecular Design of Fused-Ring Phenazine Derivatives for Long-Cycling Alkaline Redox Flow Batteries. ACS Energy Letters 2020, 5 (2), 411-417.

35. Pang, S.; Wang, X.; Wang, P.; Ji, Y., Biomimetic Amino Acid Functionalized Phenazine Flow Batteries with Long Lifetime at Near-Neutral pH. Angew Chem Int Ed 2021, 60, 5289 -5298 36. Lin, K.; Gomez-Bombarelli, R.; Beh, E. S.; Tong, L.; Chen, Q.; Valle, A.; AspuruGuzik, A.; Aziz, M. J.; Gordon, R. G., A redox-flow battery with an alloxazine-based organic electrolyte. Nature Energy 2016, 1 (9), 16102.

37. Zhao, Z.; Zhang, B.; Schrage, B. R.; Ziegler, C. J.; Boika, A., Investigations Into 
Aqueous Redox Flow Batteries Based on Ferrocene Bisulfonate. ACS Applied Energy Materials 2020, 3 (10), 10270-10277.

38. Li, Y.; Xu, Z.; Liu, Y.; Jin, S.; Fell, E. M.; Wang, B.; Gordon, R. G.; Aziz, M. J.; Yang, Z.; Xu, T., Functioning water-insoluble ferrocenes for aqueous organic flow battery via hostguest inclusion. ChemSusChem 2021, 14, 745 - 752

39. Winsberg, J.; Janoschka, T.; Morgenstern, S.; Hagemann, T.; Muench, S.; Hauffman, G.; Gohy, J. F.; Hager, M. D.; Schubert, U. S., Poly(TEMPO)/Zinc Hybrid-Flow Battery: A Novel, "Green," High Voltage, and Safe Energy Storage System. Adv Mater 2016, 28 (11), 223843.

40. Goulet, M.-A.; Tong, L.; Pollack, D. A.; Tabor, D. P.; Odom, S. A.; Aspuru-Guzik, A.; Kwan, E. E.; Gordon, R. G.; Aziz, M. J., Extending the lifetime of organic flow batteries via redox state management. J. Am. Chem. Soc. 2019, 141 (20), 8014-8019.

41. Wang, C.; Yu, B.; Liu, Y.; Wang, H.; Zhang, Z.; Xie, C.; Li, X.; Zhang, H.; Jin, Z., N-alkyl-carboxylate-functionalized anthraquinone for long-cycling aqueous redox flow batteries. Energy Storage Materials 2021, 36, 417-426.

42. Yan Jing, E. M. F., Min Wu, Shijian Jin, Yunlong Ji, Daniel A. Pollack, Zhijiang Tang, Dian Ding, Meisam Bahari, Marc-Antoni Goulet, Tatsuhiro Tsukamoto, Roy G. Gordon, Michael J.Aziz long-lifetime-potentially-low-cost-anthraquinone-flow-battery-chemistry-developed-from-studyof-effects-of-water-solubilizing-group-and-connection-to-core.

ChemRxiv

2021, (10.33774/chemrxiv-2021-0cb4d).

43. Petit, Y. K.; Mourad, E.; Prehal, C.; Leypold, C.; Windischbacher, A.; Mijailovic, D.; Slugove, C.; Borisov, S. M.; Zojer, E.; Brutti, S.; Fontaine, O.; Freunberger, S. A., Mechanism of mediated alkali peroxide oxidation and triplet versus singlet oxygen formation. Nat Chem 2021.

44. Marcus, R. A., Electron transfer reactions in chemistry. Theory and experiment. Reviews of Modern Physics 1993, 65 (3), 599-610.

45. Goulet, M.-A.; Aziz, M. J., Flow Battery Molecular Reactant Stability Determined by 
423 Symmetric Cell Cycling Methods. Journal of the Electrochemical Society 2018, 165 (7), A1466424 A1477.

425 46. McCann, G. M.; McDonnell, C. M.; Magris, L.; More O'Ferrall, R. A., Enol-keto 426 tautomerism of 9-anthrol and hydrolysis of its methyl ether. Journal of the Chemical Society, 427 Perkin Transactions 2 2002, (4), 784-795.

428 47. Liang, S.; Subrahmanyam, A. V.; Khadem, M.; Zhao, Y.; Adronov, A., Selective 429 dispersion of single-walled carbon nanotubes with electron-rich fluorene-based copolymers. RSC 430 Advances 2016, 6 (31), 25733-25740.

431

432 
436 Min Wu, ${ }^{1}$ Meisam Bahari, ${ }^{1}$ Yan Jing, ${ }^{2}$ Kiana Amini, ${ }^{1}$ Eric M. Fell, ${ }^{1}$ Thomas Y. George, ${ }^{1}$ Roy G.

437 Gordon, ${ }^{2 *}$ Michael J. Aziz ${ }^{1 *}$ 
441 Figure S1. ${ }^{1} \mathrm{H}$ NMR spectrum of 2,6-N-TSAQ in D2O-d6.

442 Figure S2. LC-MS traces of the synthesized 2,6-N-TSAQ.

444 Figure S3. ${ }^{1} \mathrm{H}$ NMR spectrum of 2,6-O-DPSAQ in DMSO-d6.

445 Synthesis of 2,6-DPSAQ

446 Figure S4. ${ }^{1} \mathrm{H}$ NMR spectrum of 2,6-DPSAQ in DMSO-d6.

447 Table S1. The lab-scale cost of 2,6-DHAQ, 2,6-DAAQ and 1,3-propanesultone are from Sigma448 Aldrich in July 2021 34

449 Figure S5. Cyclic voltammograms of $5 \mathrm{mM}$ 2,6-N-TSAQ in 1 M sodium hydroxide at a scan rate 450 of $100 \mathrm{mV} / \mathrm{s}$ 34

451 Figure S6. UV-vis absorbance spectra for 2,6-N-TSAQ 36

452 Figure S7. UV-vis of H-cell measurement. 37

453 Figure S8. CV of $2 \mathrm{mM}$ 2,6-N-TSAQ in different $\mathrm{pH}$ buffer solutions at a sweep rate of $100 \mathrm{mV} / \mathrm{s}$.

455 Figure S9. Electrochemical kinetics of 2,6-N-TSAQ in $1 \mathrm{M} \mathrm{NaOH}$. 39

456 Full cell measurements 40

457 Figure S10. Energy efficiency and capacity contribution percentage at voltage hold at $0.6 \mathrm{~V}$ versus 458 cycle number of the $0.1 \mathrm{M}$ 2,6-N-TSAQ/ferrocyanide cell in $1 \mathrm{M}$ sodium chloride solution 41 
459 Figure S11. Cell performance of $0.1 \mathrm{M}$ 2,6-N-TSAQ/ferrocyanide cell in 1M NH4Cl supporting

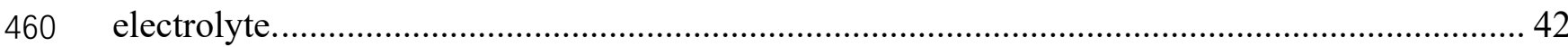

461 Figure $\mathrm{S} 12 .{ }^{1} \mathrm{H}$ NMR spectra $(500 \mathrm{MHz})$ of the cycled 2,6-N-TSAQ in $1 \mathrm{M} \mathrm{NH}_{4} \mathrm{Cl}$ electrolyte

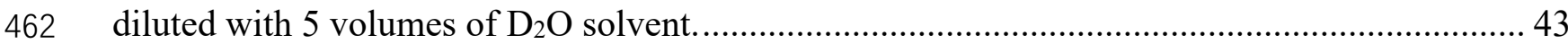

463 Figure S13. The mass spectrum of the cycled 2,6-NTSAQ $\left(\mathrm{NH}_{4} \mathrm{Cl}\right)$ electrolyte. .......................... 44

464 Figure S14. ${ }^{1} \mathrm{H}$ NMR spectra $(400 \mathrm{MHz})$ of 2,6-N-TSAQ in $\mathrm{D}_{2} \mathrm{O}$ solvent. ................................. 45

465

466 


\section{Experimental Materials:}

2,6-diaminoanthraquione (97\%), 1,3-propanesultone (98\%), sodium hydride (60\% in mineral

oil), anhydrous dimethyl sulfoxide, anhydrous N,N-Dimethylformamide, potassium carbonate,

\section{Synthesis of 2,6-N-TSAQ}

$4753 \mathrm{~g}$ of 2,6-diaminoanthraquinone $(12.59 \mathrm{mmol})$ was added to $50 \mathrm{~mL}$ anhydrous dimethyl sulfoxide.

476 Then $2.1 \mathrm{~g}$ sodium hydride $(60 \%, 52.46 \mathrm{mmol})$ was added to the solution under vigorous stirring.

477 After 15 minutes, $6.41 \mathrm{~g}$ 1,3-propanesultone $(98 \%, 52.46 \mathrm{mmol})$ was added to the above mixture.

478 The solution was stirred at room temperature for overnight. Afterward, ethyl acetate was added to

479 the solution and collect the red solid. The crude product was further washed with ethyl acetate to 480 remove any mineral oil. Yield:9.7 g (95\%).

481 The ${ }^{1} \mathrm{H}$ NMR spectrum of 2,6-N-TSAQ is shown in Figure $\mathrm{S} 1$. 


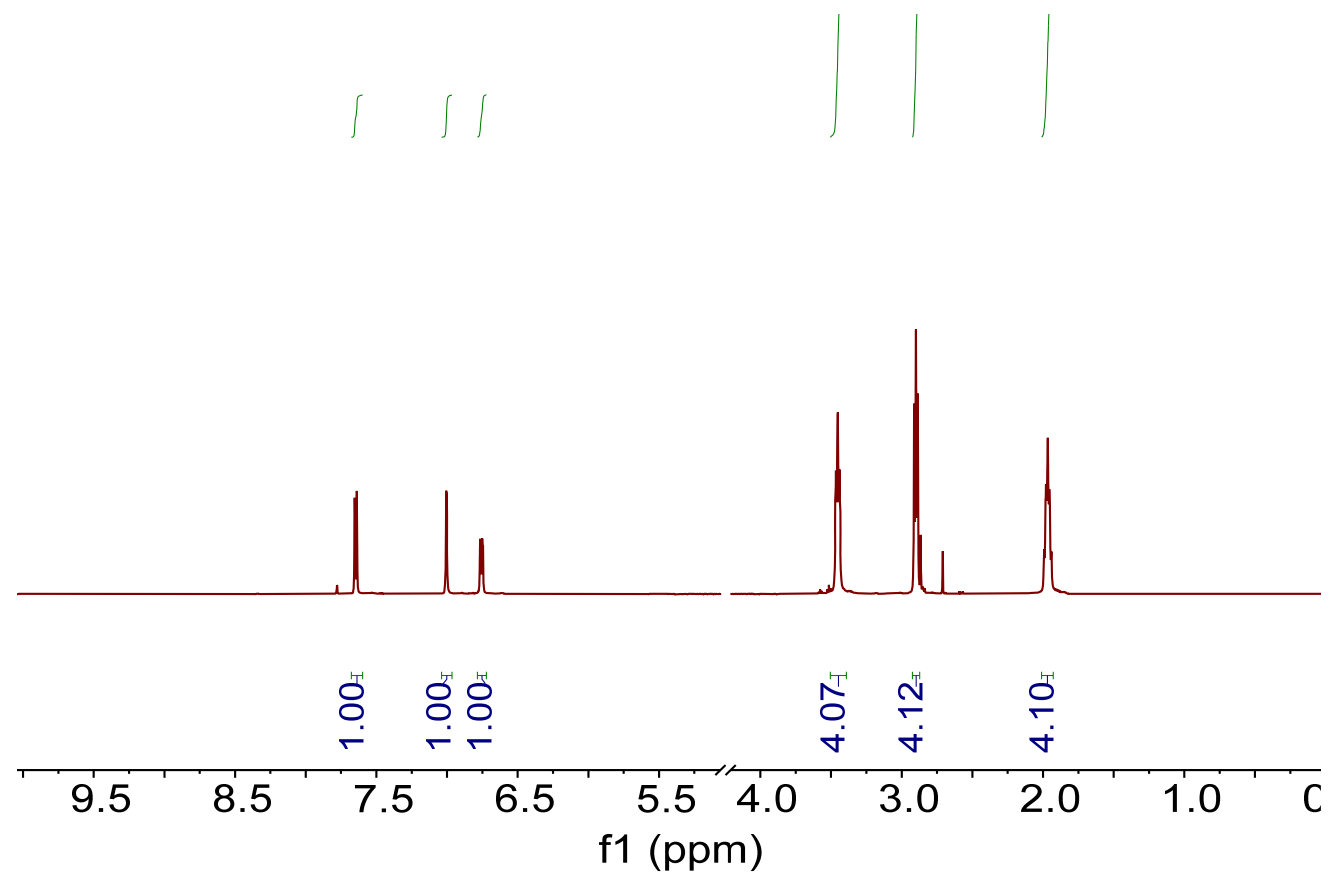

482

483

484

485

486

Figure S1. ${ }^{1} \mathrm{H}$ NMR spectrum of 2,6-N-TSAQ in D2O-d6. Solvent peak at $4.7 \mathrm{pm}$ was censored

to increase other peaks. ${ }^{1} \mathrm{H}$ NMR $\left(500 \mathrm{MHz}, \mathrm{D}_{2} \mathrm{O}\right) \delta 7.65(\mathrm{~d}, 2 \mathrm{H}), 7.00(\mathrm{~d}, 2 \mathrm{H}), 6.76(\mathrm{dd}, 2 \mathrm{H}), 3.45$ $(\mathrm{t}, 8 \mathrm{H}), 2.90(\mathrm{t}, 8 \mathrm{H}), 1.97(\mathrm{~m}, 8 \mathrm{H})$. 

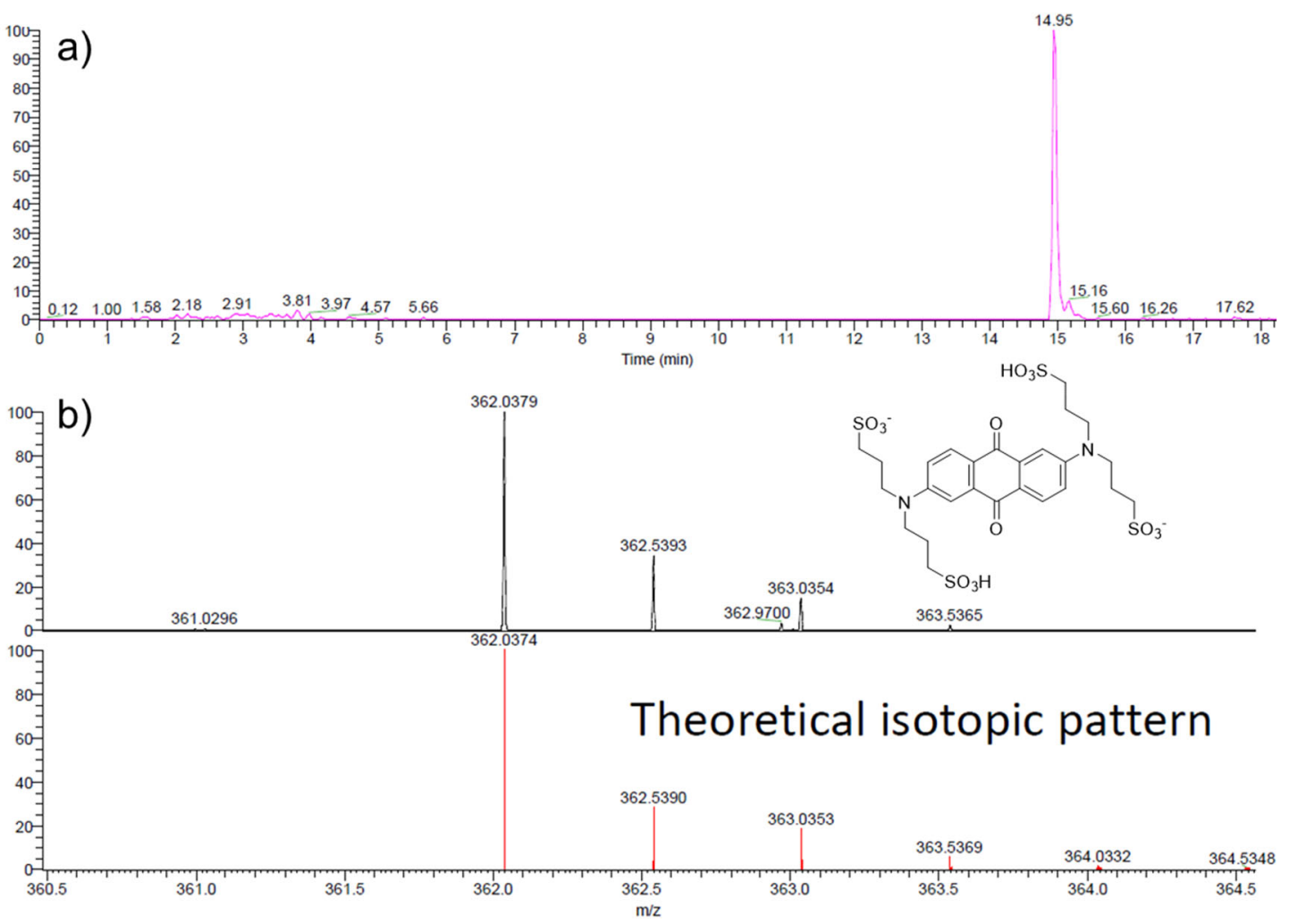

Figure S2. LC-MS traces of the synthesized 2,6-N-TSAQ. a) LC trace of 2,6-N-TSAQ; b) Mass spectrum of the material eluted at $14.95 \mathrm{~min}$ in the LC trace. The peak at $\mathrm{m} / \mathrm{z}=362.04$ corresponding to the 2,6-N-TSAQ with two protonate form and two negative charges. Sample preparation: 0.1 M 2,6-N-TSAQ was diluted 100 times with HPLC water, and further diluted 100 times with acetonitrile/water co-solvents $(\mathrm{V} / \mathrm{V}=1: 1)$ to the desired concentration $10 \mu \mathrm{M}$. Highresolution LC-MS analysis was performed in the Small Molecule Mass Spectrometry Facility at

494 Harvard University on a MiniLIMS. The elution solution is $0.1 \% \mathrm{v} / \mathrm{v}$ formic acid in acetonitrile.

495 The ESI mass spectrum was recorded in negative ionization mode. 


\section{Synthesis of 2,6-O-DPSAQ}

$4983 \mathrm{~g}$ of 2,6-dihydroxyanthraquinone (12.49 $\mathrm{mmol}$ ) was added to $50 \mathrm{~mL}$ anhydrous N,N-

Dimethylformamide. Then $1.05 \mathrm{~g}$ sodium hydride $(60 \%, 26.23 \mathrm{mmol})$ was added to the solution added to the above mixture. The solution was stirred at room temperature for overnight.

504 The ${ }^{1} \mathrm{H}$ NMR spectrum of 2,6-O-DPSAQ is shown in Figure S3.

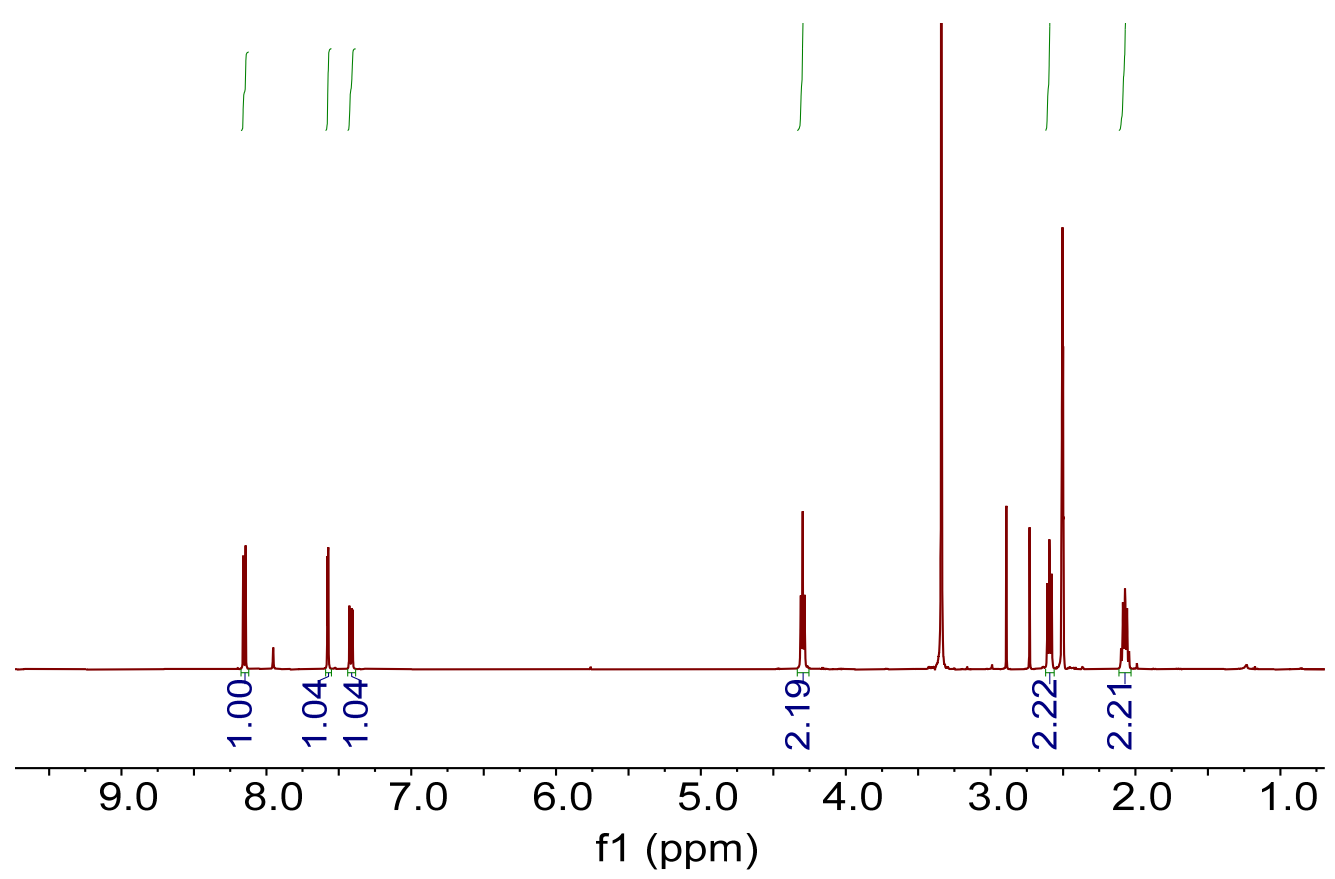

Figure S3. ${ }^{1} \mathrm{H}$ NMR spectrum of 2,6-O-DPSAQ in DMSO-d6. Solvent peaks are those not integrated. ${ }^{1} \mathrm{H}$ NMR (500 MHz, DMSO-d6) $\delta 8.15(\mathrm{~d}, 2 \mathrm{H}), 7.58(\mathrm{~d}, 2 \mathrm{H}), 7.42(\mathrm{dd}, 2 \mathrm{H}), 4.30(\mathrm{t}$, 4H), 2.59 (t, 4H), 2.07 (m, 4H). 


\section{Synthesis of 2,6-DPSAQ}

511 2,6-diiodoanthraquinone was synthesized according to the reported procedure. ${ }^{47}$

512 Heat a mixture of 2 g 2,6-diiodoanthraquinone (4.35 mmol), 0.75 g sodium

513 allylsulfonate $(5.22 \mathrm{mmol}), 0.72 \mathrm{~g}$ potassium carbonate $(5.22 \mathrm{mmol})$ and $49 \mathrm{mg}$

514 palladium acetate $(0.22 \mathrm{mmol})$ in $40 \mathrm{~mL}$ water in a pressure vessel to $120{ }^{\circ} \mathrm{C}$ for

515 overnight. The mixture solution was filtered to remove insoluble gradients. Collect

516 the filtrate and add it to a $20 \mathrm{~mL}$ methanol. The solution was stirred in a hydrogen

517 atmosphere for overnight.

518 Evaporate the solution in vacuum to collect the solid. Yield: $1.51 \mathrm{~g}(70 \%)$.

519 The ${ }^{1} \mathrm{H}$ NMR spectrum of 2,6-DPSAQ is shown in Figure S4.

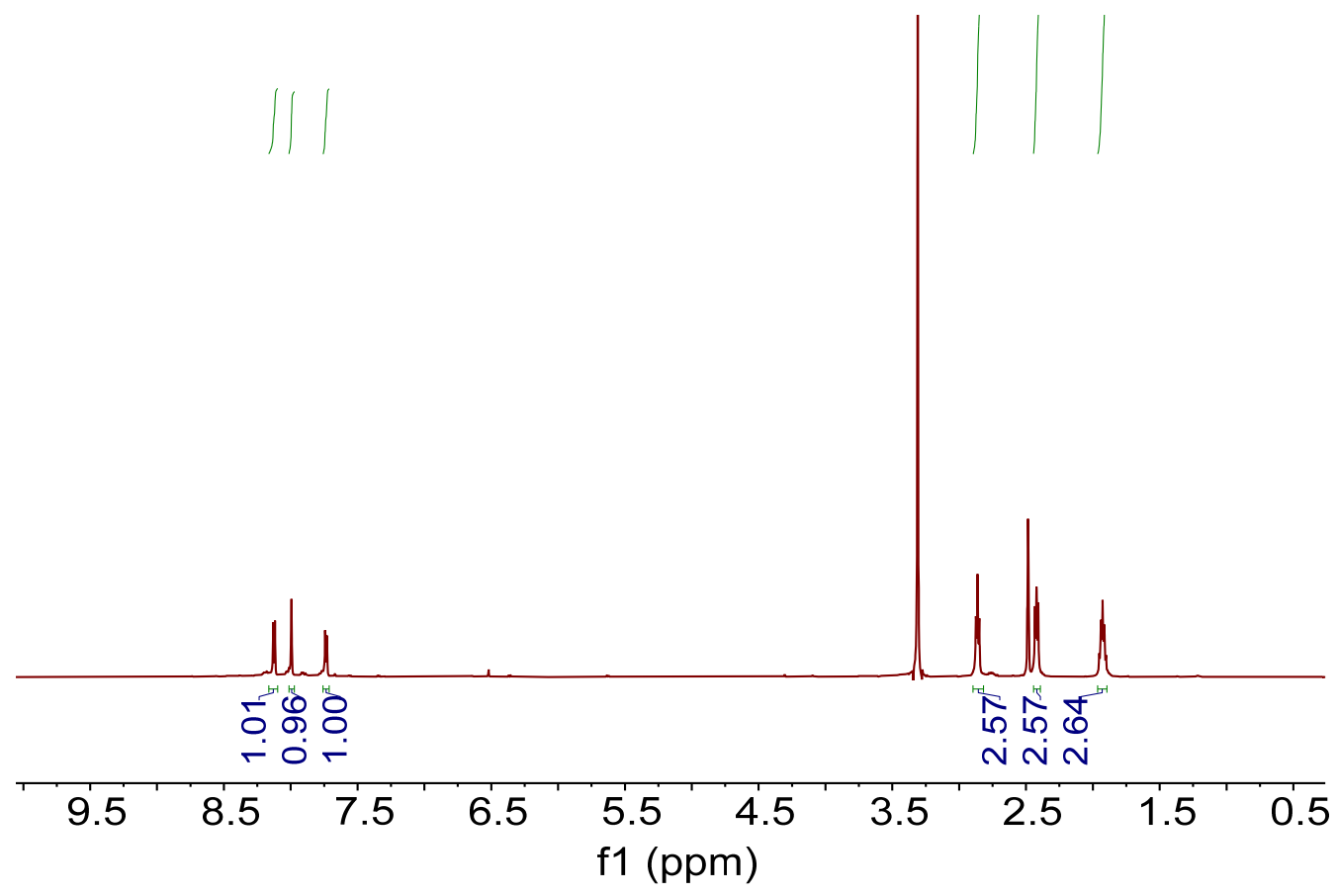

521 Figure S4. ${ }^{1} \mathrm{H}$ NMR spectrum of 2,6-DPSAQ in DMSO-d6. Solvent peaks are those not

522 integrated. ${ }^{1} \mathrm{H}$ NMR (500 MHz, DMSO-d6) $\delta 8.12(\mathrm{~d}, 2 \mathrm{H}), 7.99(\mathrm{~d}, 2 \mathrm{H}), 7.74(\mathrm{dd}, 2 \mathrm{H}), 2.86(\mathrm{t}$, 
$5234 \mathrm{H}), 2.42(\mathrm{t}, 4 \mathrm{H}), 1.93(\mathrm{~m}, 4 \mathrm{H})$.

524 
Table S1. The lab-scale cost of 2,6-DHAQ, 2,6-DAAQ and 1,3-propanesultone are from SigmaAldrich in July 2021.

\begin{tabular}{c|c}
\hline Molecules & Lab-Scale Cost (\$/Mol) \\
\hline $2,6-$ DHAQ & 364 \\
\hline 2,6 -DAAQ & 6918 \\
\hline $1,3-$ propanesultone & 77 \\
\hline
\end{tabular}

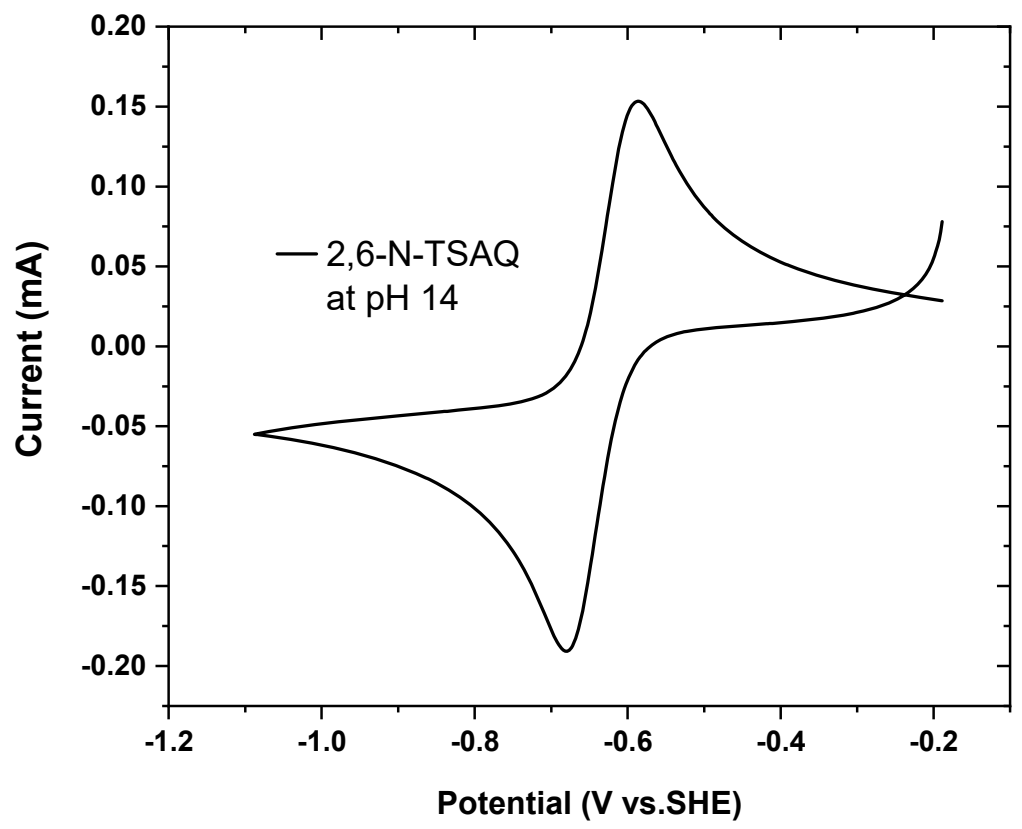
of $100 \mathrm{mV} / \mathrm{s}$. 


\section{UV-vis and permeability measurements}

UV-vis absorbance spectra for calibration curves and crossover detection were taken using an Agilent 8453 spectrophotometer. The permeability of 2,6-N-TSAQ through Nafion NR212 cation exchange membrane was measured in a custom two-compartment diffusion cell ("H-cell”) made by Adams \& Chittenden scientific glassware. The Nafion NR212, received protonated, was ion exchanged to sodium form in $1 \mathrm{M} \mathrm{NaOH}$ by soaking for over 12 hours at ambient temperature. This membrane was sealed between a donating compartment containing $10 \mathrm{~mL}$ of $0.1 \mathrm{M} 2,6-\mathrm{N}-$ TSAQ in $1 \mathrm{M} \mathrm{NaOH}$ and a receiving compartment containing $10 \mathrm{~mL}$ of $0.17 \mathrm{M} \mathrm{Na}_{2} \mathrm{SO}_{4}$ in $1 \mathrm{M}$ $\mathrm{NaOH}$. The electrolyte in the receiving compartment was designed to minimize osmotic pressure gradients influencing permeability: a freezing point osmometer (Advanced Instruments Inc., Model 3300) confirmed the osmolarity difference between the compartments was only 0.018 Osm. Both compartments were stirred continuously using magnetic stir bars.

Three identical H-cells stirred for 13 days, and $2 \mathrm{~mL}$ aliquots were periodically removed from the receiving side to measure absorbance spectra, which were then replaced with fresh receiving solution. Due to the exceptionally low crossover rate, the spectrophotometer was unable to detect the peaks characteristic of 2,6-N-TSAQ, so an upper limit was assigned based on the highest absorbance value observed at $455 \mathrm{~nm}$ during the experiment (Fig S8). Using the derivation of Fick's Law reported previously, ${ }^{1}$ 2,6-N-TSAQ cannot exceed $3 \times 10^{-14} \mathrm{~cm}^{2} / \mathrm{s}$ under these conditions. 

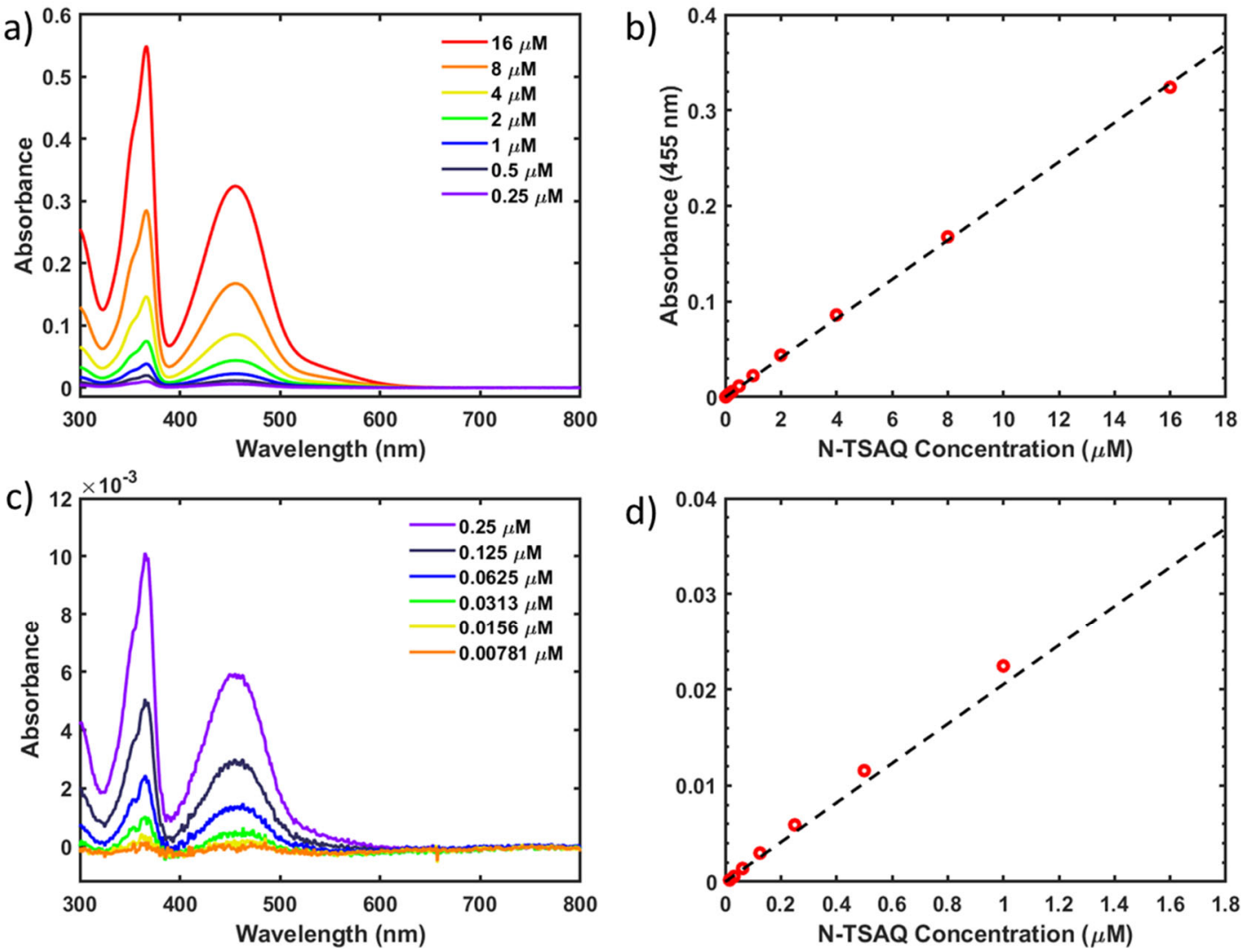

554 Figure S6. UV-vis absorbance spectra for 2,6-N-TSAQ at concentrations of a) $16 \mu \mathrm{M}$ to 0.25

$555 \mu \mathrm{M}$ and c) $0.25 \mu \mathrm{M}$ to $0.00781 \mu \mathrm{M}$ in $1 \mathrm{M} \mathrm{NaOH}$. Solutions were prepared by serial 2:1 dilution

556 approaching the detection limit of the spectrophotometer. A baseline of zero absorbance at 750

$557 \mathrm{~nm}$ was applied to all spectra. The slope of the resulting calibration curve in panels b) and d)

558 (10x zoom in to the origin of $b$ ) gives a molar attenuation coefficient of $0.0205 \mu \mathrm{M}^{-1} \mathrm{~cm}^{-1}$. 


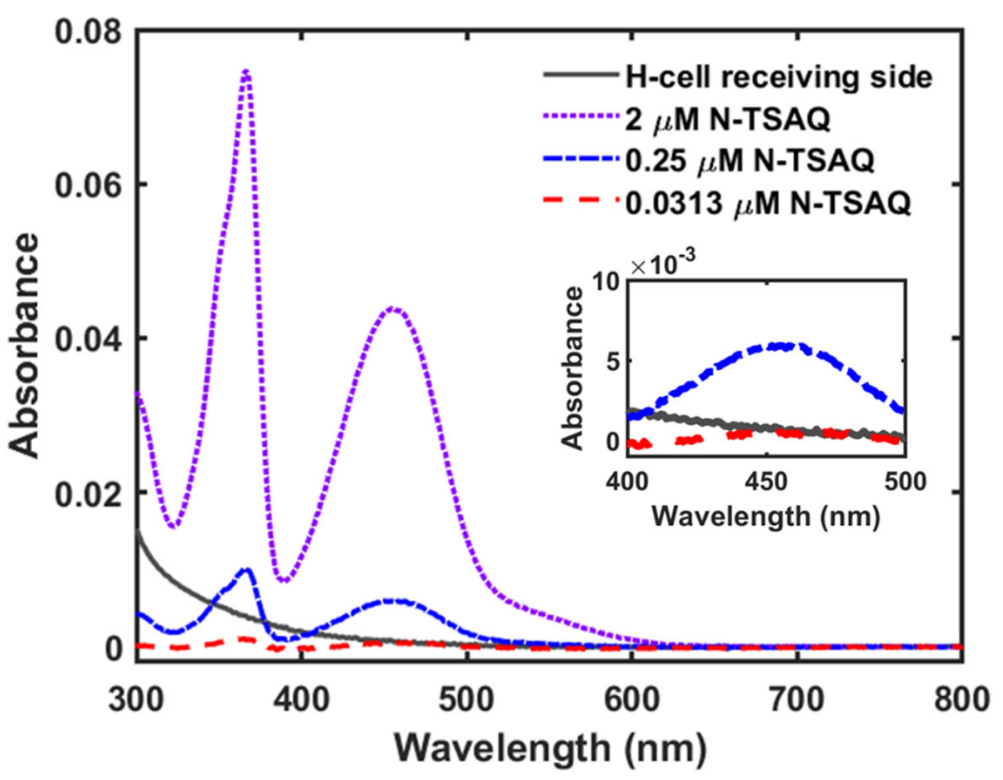

560 Figure S7. UV-vis of H-cell measurement. The grey trace is the UV-vis absorbance spectrum of

561 the receiving solution of a two-compartment diffusion $\mathrm{H}$-cell which exhibited the highest

562 absorbance at $455 \mathrm{~nm}$ over 13 days. This absorbance was used to calculate an upper limit on the

563 permeability of 2,6-N-TSAQ through Nafion NR212 because the peaks indicative of 2,6-N-

564 TSAQ were not detectable by the spectrophotometer. Therefore, the permeability cannot be

565 greater than $3 \times 10^{-14} \mathrm{~cm}^{2} / \mathrm{s}$. The small absorbance at 300-400 $\mathrm{nm}$ indicates a minor impurity

566 which does not interfere with the 2,6-N-TSAQ peak at $455 \mathrm{~nm}$. 


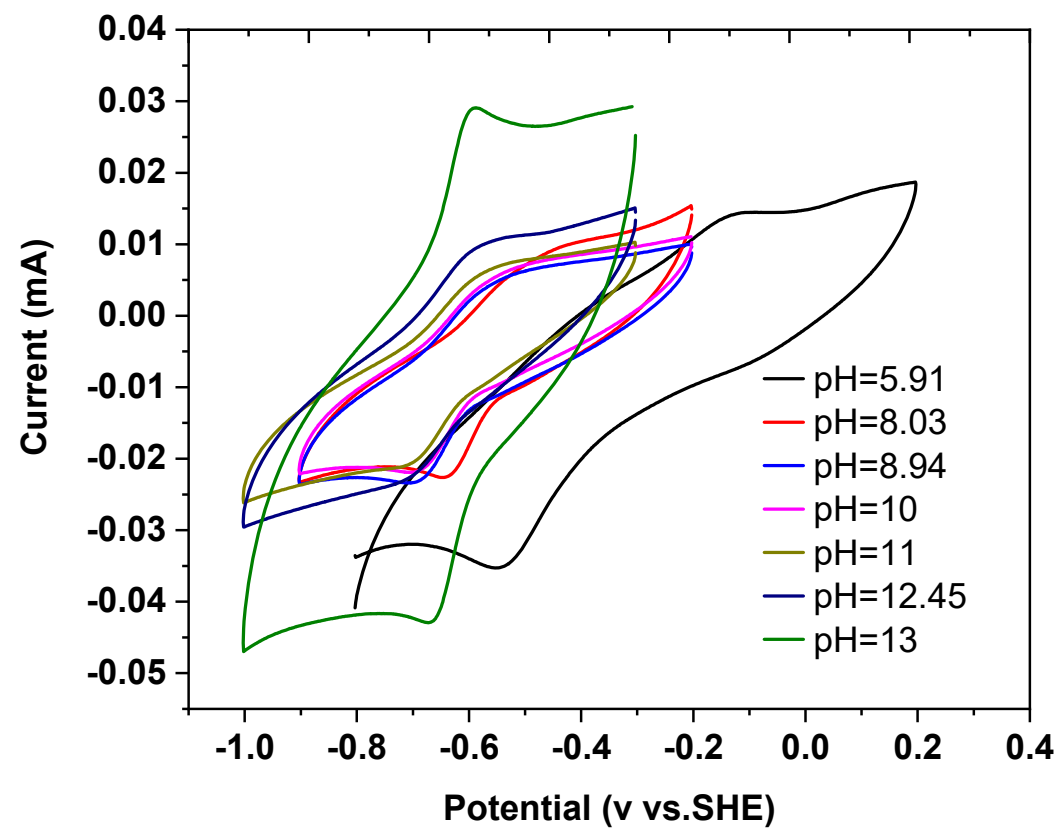

568

Figure S8. CV of $2 \mathrm{mM}$ 2,6-N-TSAQ in different $\mathrm{pH}$ buffer solutions at a sweep rate of $100 \mathrm{mV} / \mathrm{s}$. 

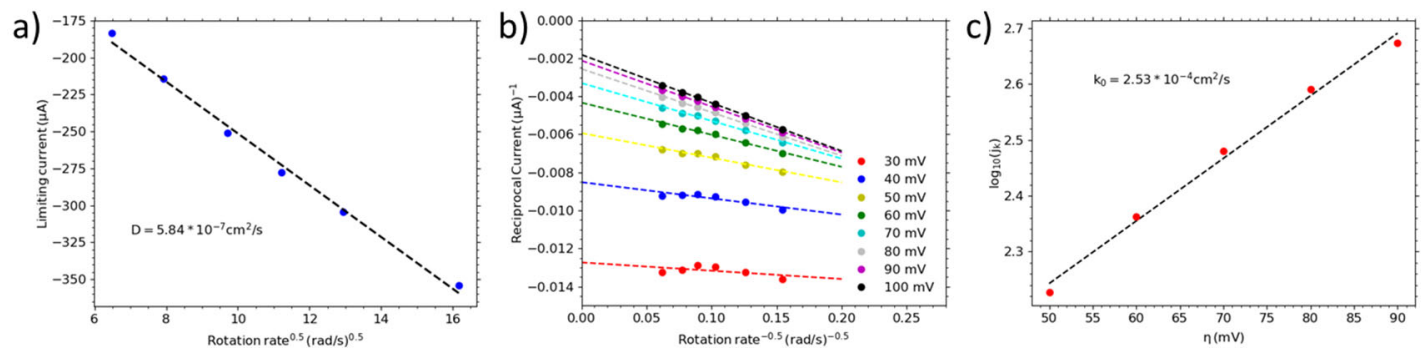

573 Figure S9. Electrochemical kinetics of 2,6-N-TSAQ in $1 \mathrm{M} \mathrm{NaOH}$. a) Levich plot (limiting current

574 versus square root of rotation rate) of $5 \mathrm{mM}$ 2,6-N-TSAQ in $1 \mathrm{M} \mathrm{NaOH}$. Limiting current is taken

575 as the current at $-0.8 \mathrm{~V}$ vs SHE in Figure $3 \mathrm{~b}$. The slope yields a diffusion coefficient for the 2,6-

576 N-TSAQ of $5.84 \times 10^{-7} \mathrm{~cm}^{2} / \mathrm{s}$; b) Koutecký-Levich plot (reciprocal current versus inverse square

577 root of rotation rate) of $5 \mathrm{mM} 2,6-\mathrm{N}-\mathrm{TSAQ}$ in $1 \mathrm{M} \mathrm{NaOH}$; c) Fitted Tafel plot of $5 \mathrm{mM}$ 2,6-N-

578 TSAQ in $1 \mathrm{M} \mathrm{NaOH}$. The charge transfer coefficient is calculated to be 0.32 , and the rate constant

579 is calculated to be $2.53 \times 10^{-4} \mathrm{~cm} / \mathrm{s}$.

580 


\section{Full cell measurements}

Flow battery experiments were performed with cell and hardware from Fuel Cell Tech.

(Albuquerque, NM). Pyrosealed POCO graphite flow plates with serpentine flow designs were used for both electrodes. Each electrode comprised a $5 \mathrm{~cm}^{2}$ geometric surface area enclosed by one piece of AvCarb carbon electrode. For 2,6-N-TSAQ/ferrocyanide full cell tests, a Nafion ${ }^{\mathrm{TM}}$ 212 membrane was used to serve as the ion-selective membrane. The Nafion membrane was soaked in the supporting electrolyte (sodium hydroxide or sodium chloride) for at least 24 hours before use. Viton sheets were used to cover the outer portion space between the electrodes.

Torque used for cell assembly was $60 \mathrm{lb}$-in $(6.78 \mathrm{Nm})$ on each of eight 1/4-28 bolts. The electrolytes were input into the cell through fluorinated ethylene propylene (FEP) tubing at a rate of $60 \mathrm{~mL} / \mathrm{min}$, controlled by Cole-Parmer 6 Masterflex L/S peristaltic pumps. The cell was run inside a glove box $\left(1 \mathrm{ppm} \mathrm{O}_{2}\right)$. Cell polarization measurements and charge-discharge cycling were conducted using a Biologic BCS-815 battery cycler. Long-term cycling of the $0.1 \mathrm{M} 2,6-\mathrm{N}$ $\mathrm{TSAQ} /$ ferrocyanide cell was achieved at $\pm 40 \mathrm{~mA} \mathrm{~cm}^{-2}$ with potential holds at $1.4 \mathrm{~V}$ for charging and $0.6 \mathrm{~V}$ for discharging until the current density dropped to $2 \mathrm{~mA} \mathrm{~cm}^{-2}$. The polarization curves were obtained by charging to a desired state of charge first and then polarizing via linear sweep voltammetry at a rate of $100 \mathrm{mV} \mathrm{s}^{-1}$.

A glassy carbon (BASi, $3 \mathrm{~mm}$ diameter) working electrode, an $\mathrm{Ag} / \mathrm{AgCl}$ reference electrode (BASi, $3 \mathrm{M} \mathrm{NaCl}$ solution), and a graphite counter electrode were used in the three-electrode system for all CV tests. 
601

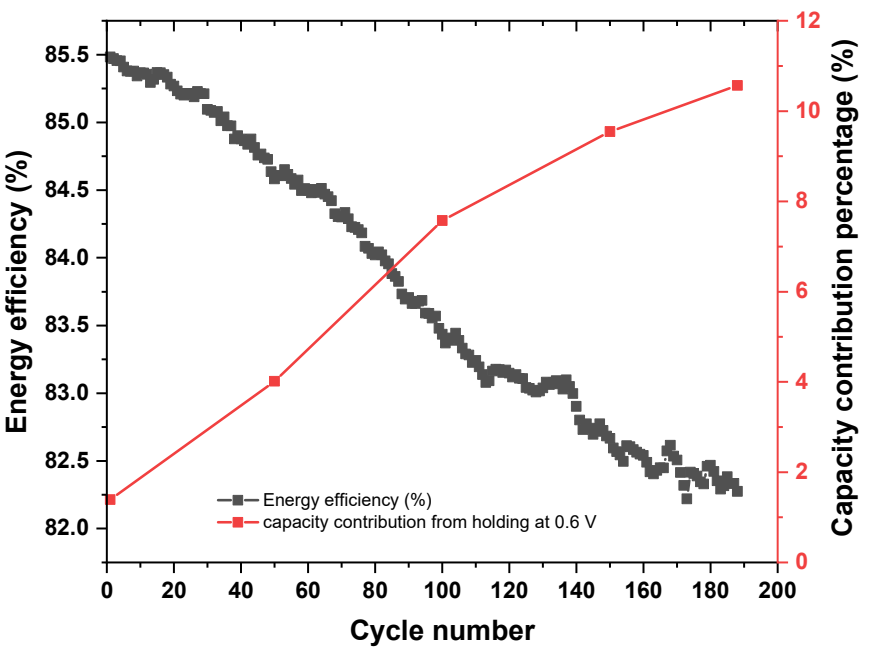

603 Figure S10. Energy efficiency and capacity contribution percentage at voltage hold at $0.6 \mathrm{~V}$

604 versus cycle number of the $0.1 \mathrm{M}$ 2,6-N-TSAQ/ferrocyanide cell in $1 \mathrm{M}$ sodium chloride 605 solution.

606 

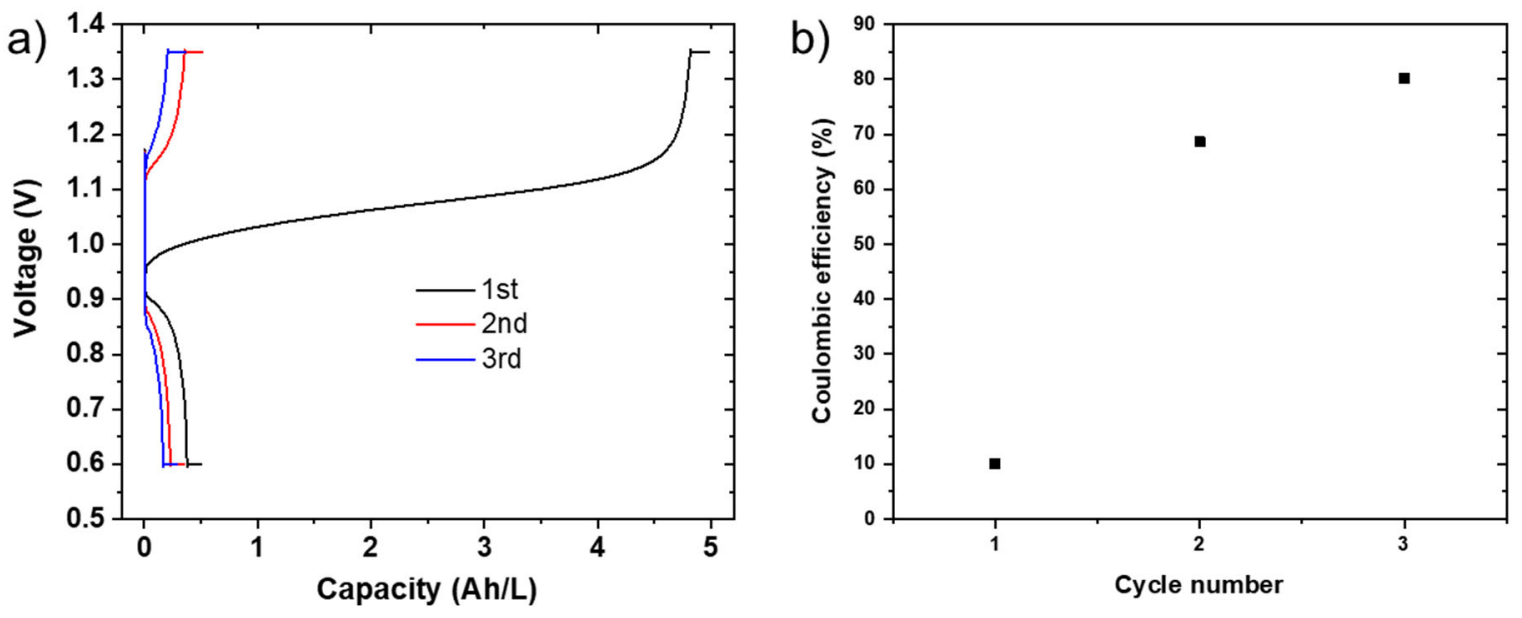

607

Figure S11. Cell performance of $0.1 \mathrm{M} 2,6-\mathrm{N}-\mathrm{TSAQ} /$ ferrocyanide cell in $1 \mathrm{M} \mathrm{NH} 4 \mathrm{Cl}$ supporting

609 electrolyte. a) Charge-discharge voltage profile of 0.1 M 2,6-N-TSAQ/ferrocyanide full cell in 1

$610 \mathrm{M} \mathrm{NH}_{4} \mathrm{Cl}$ at $\mathrm{pH} 7$. b) The corresponding coulombic efficiency for $0.1 \mathrm{M} 2,6-\mathrm{N}$ -

$611 \mathrm{TSAQ}$ /ferrocyanide cell in $1 \mathrm{M} \mathrm{NH}_{4} \mathrm{Cl}$ condition. Cell condition: $5 \mathrm{~mL} 0.1 \mathrm{M}$ 2,6-N-TSAQ in 1

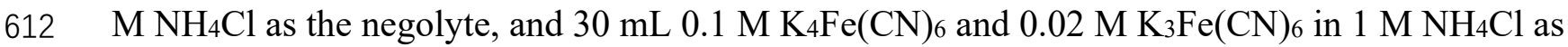

613 the posolyte, both electrolytes are tuned to $\mathrm{pH} 7$ with sodium hydroxide.

614 

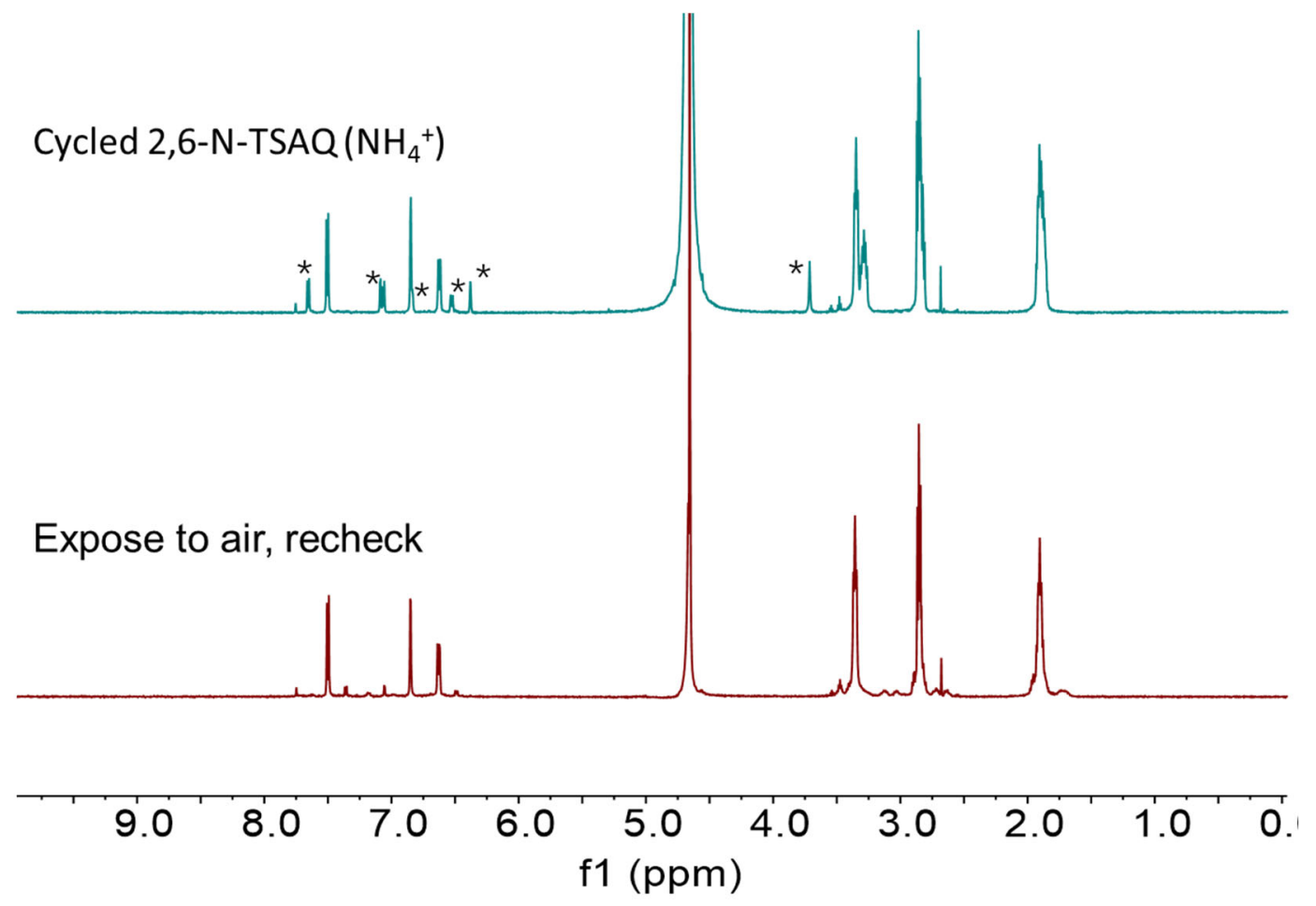

Figure S12. ${ }^{1} \mathrm{H}$ NMR spectra $(500 \mathrm{MHz})$ of the cycled 2,6-N-TSAQ in $1 \mathrm{M} \mathrm{NH}_{4} \mathrm{Cl}$ electrolyte

617 diluted with 5 volumes of $\mathrm{D}_{2} \mathrm{O}$ solvent. The asterisk peaks belong to anthrone, after fully air

618 aerated, the anthrone peaks disappeared.

619

620

621 


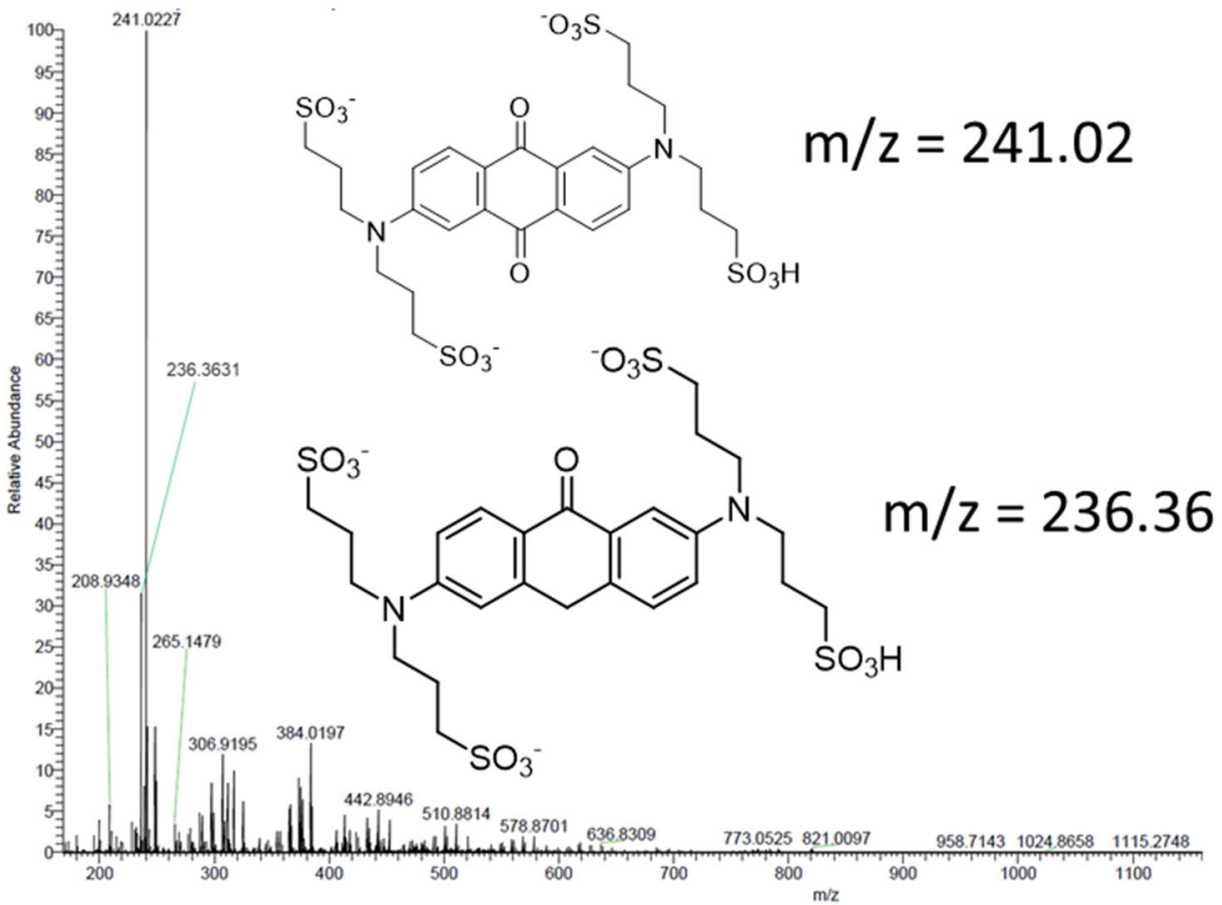

Figure S13. The mass spectrum of the cycled 2,6-NTSAQ $\left(\mathrm{NH}_{4} \mathrm{Cl}\right)$ electrolyte. The

624 electrolyte was diluted 10,000 times with HPLC water and directly analyzed with 625 mass spectrometry. The $\mathrm{m} / \mathrm{z}$ peak at 236.36 belongs to the anthrone peak, and peak 626 at 241.02 belong to $2,6-\mathrm{N}-\mathrm{TSAQ}$.

627 

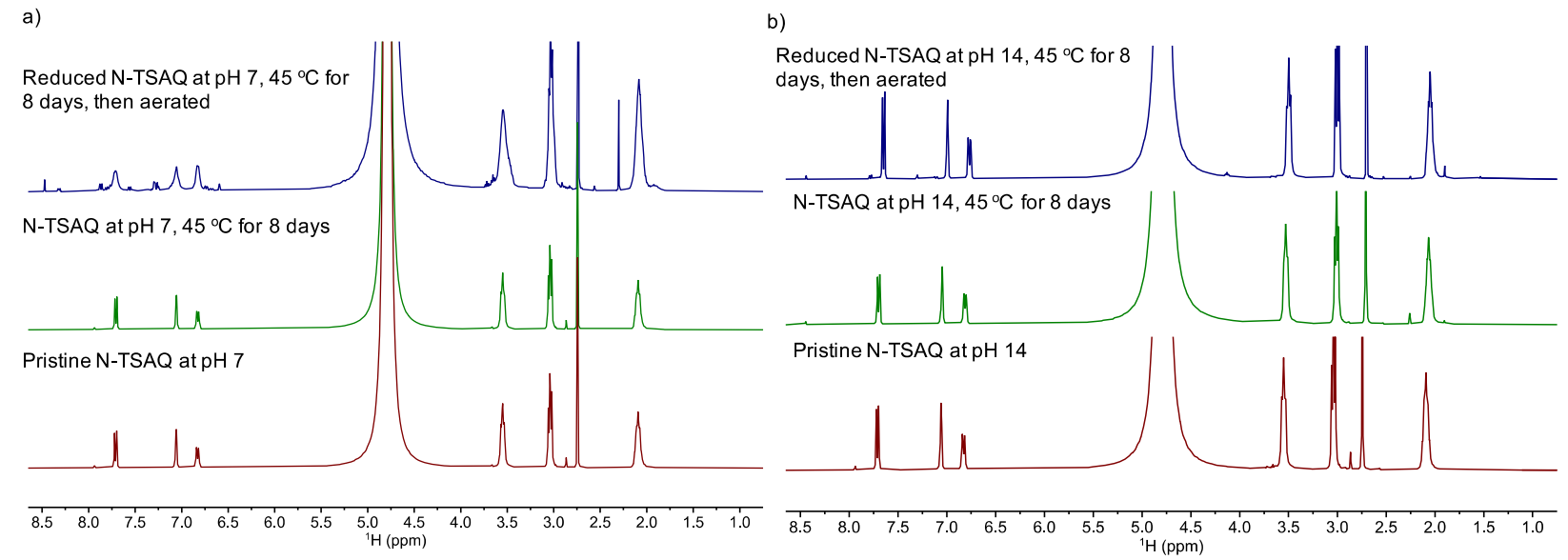

Figure S14. ${ }^{1} \mathrm{H}$ NMR spectra (400 MHz) of 2,6-N-TSAQ in $\mathrm{D}_{2} \mathrm{O}$ solvent. (a) from bottom

629 to top: pristine 2,6-N-TSAQ; $0.1 \mathrm{M} \mathrm{2,6-N-TSAQ} \mathrm{in} 1 \mathrm{M} \mathrm{NaCl}$ at $45^{\circ} \mathrm{C}$ for 8 days;

$0.1 \mathrm{M}$ reduced form of 2,6-N-TSAQ in $1 \mathrm{M} \mathrm{NaCl}$ at $45^{\circ} \mathrm{C}$ for 8 days, then aerated;

(b) from bottom to top: pristine 2,6-N-TSAQ; $0.1 \mathrm{M} \mathrm{2,6-N-TSAQ} \mathrm{in} 1 \mathrm{M} \mathrm{NaOH}$ at

$45^{\circ} \mathrm{C}$ for 8 days; $0.1 \mathrm{M}$ reduced form of 2,6-N-TSAQ in $1 \mathrm{M} \mathrm{NaOH}$ at $45{ }^{\circ} \mathrm{C}$ for 8 days, then aerated. 
635 References

636 1. Kwabi, D. G.; Lin, K.; Ji, Y.; Kerr, E. F.; Goulet, M.-A.; De Porcellinis, D.;

637 Tabor, D. P.; Pollack, D. A.; Aspuru-Guzik, A.; Gordon, R. G.; Aziz, M. J.,

638 Alkaline quinone flow battery with long lifetime at pH 12. Joule 2018, 2 (9),

639 1907-1908.

640 